\title{
CrystEngComm
}

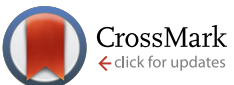

Cite this: CrystEngComm, 2015, 17, 2754

Received 7th November 2014 Accepted 13th February 2015

DOI: $10.1039 / c 4 c e 02215 g$

www.rsc.org/crystengcomm

\section{Architectures varying from discrete molecular units to 2-dimensional coordination polymers and photoluminescence behavior of zinc and cadmium comprising an anionic zwitterion of rigid 4,5- dicarboxy-1,3-dimethyl-1 $H$-imidazolium iodide $\dagger$}

\author{
Sarita Tripathi and Ganapathi Anantharaman*
}

\begin{abstract}
A rigid imidazolium dicarboxylate ligand, 4,5-dicarboxy-1,3-dimethyl- $1 \mathrm{H}$-imidazolium iodide $\left(\mathrm{H}_{2} \mathrm{DDII}\right)$, was synthesized and employed in the construction of metal complexes or coordination polymers (CPs) comprising an anionic zwitterion (DDI $)^{-}$, namely, $\left[\mathrm{Zn}(\mathrm{Cl})\left(\mathrm{H}_{2} \mathrm{O}\right)_{2}(\mathrm{DDI})\right] \cdot\left(\mathrm{H}_{2} \mathrm{O}\right)(2),\left\{\left[\mathrm{Zn}_{2}(\mathrm{DDI})_{3}\left(\mathrm{H}_{2} \mathrm{O}\right)_{2}\right] \cdot \mid\right\}_{n}(3)$, $\left[\mathrm{Zn}_{2}(\mathrm{DDI})_{2} \mathrm{I}\right] \cdot 2 \mathrm{H}_{2} \mathrm{O}$ (4), $\left[\mathrm{Zn}(\mathrm{DDI})_{2}\left(\mathrm{H}_{2} \mathrm{O}\right)_{3}\right] \cdot\left(\mathrm{H}_{2} \mathrm{O}\right)_{2}$ (5) and $\left[\mathrm{Cd}(\mathrm{DDI})_{2}\right]_{n}$ (6). In addition, the ligand upon crystallization forms a zwitterion, [HDDI, (1)] by losing $\mathrm{HI}$ and shows both intra- and intermolecular $\mathrm{H}$-bonding and an interesting intermolecular $\mathrm{C}=\mathrm{O} \cdots \mathrm{C}$ short contact. The carboxylate unit of the ligand exhibits terminal monodentate and bidentate chelate modes of coordination. The stoichiometric ratio of metal to ligand, nature of base, type of metal salt and solvent conditions affected the architectures and dimensionality of 2-6 from zero dimensional monomers and dimers to 2D coordination polymers (CPs). Complex 2 forms a discrete molecular unit extended by supramolecular interactions to form 2D rectangular sheets. In 3, a crown shaped macrocycle results in a 2D herringbone CP and extends to a 3D supramolecular architecture on account of a coordination network containing trapped iodide as counter anions. Complex 4 forms a dimer with coordinated iodide ions and forms an infinite 1D ladder shaped supramolecular architecture. Complex 5 forms another discrete molecular unit different from 2, and extends to a 3D architecture through supramolecular interactions. Complex 6 forms a 2D CP with Cd(॥) forming an interesting "fish scale pattern" and lacks any counter anion or solvent molecules. Additionally, the thermal stability of complexes 2-6 was analyzed by thermogravimetric analysis. In addition, the solid state photoluminescence properties of $\mathrm{H}_{2} \mathrm{DD}$ II and compounds 2-6 were investigated at room temperature.
\end{abstract}

\section{Introduction}

The coordination polymers (CPs) or Metal Organic Frameworks (MOFs) constructed by ligands consisting of carboxylate donor groups are one of the main research areas studied over the last two decades. ${ }^{1}$ CPs comprising carboxylate donor atoms have been employed in a wide range of applications including gas storage, separation, magnetism, luminescence and catalysis. ${ }^{2,3}$ Multidentate carboxylate donor ligands on account of their diverse coordination modes adopt variable conformations and hence have proven to be excellent candidates for the construction of CPs or MOFs with diverse

Department of Chemistry, Indian Institute of Technology Kanpur, Kanpur-208016, India. E-mail: garaman@iitk.ac.in

$\dagger$ Additional figures, TGA, powder X-ray diffraction patterns. X-ray crystallographic data in CIF format have been deposited with the Cambridge Structural Database. CCDC 1027616-1027621 contains the supplementary crystallographic data for this paper. For crystallographic data in CIF or other electronic format see DOI: $10.1039 / \mathrm{c} 4 \mathrm{ce} 02215 \mathrm{~g}$ architectures. This study was extended to the design and synthesis of CPs having N-heterocyclic carboxylate ligands of pyridine, pyrazole and imidazole because of the available mixed multidentate coordination sites including nitrogen and oxygen centers as donor atoms to the metal ions. The presence of an $\mathrm{N}$-heterocyclic unit as well as multiple carboxylate units, with various deprotonated forms, allows for the various coordination modes resulting in different topologies. ${ }^{4-6}$ In this context, imidazole-4,5-dicarboxylic acid ( $\left.\mathrm{H}_{3} \mathrm{IDC}\right)$ and its different analogue ligands as linkers have been mainly used for the synthesis of novel CPs. ${ }^{7-10}$

Functionalized CPs having primary and secondary functional groups have been used as supports and employed in catalysis, wherein the primary functional group coordinates to the metal centre to form an extended network, while the secondary functional group acts as the catalytic site. ${ }^{11}$ For the past two decades, imidazolium based ligands have been potentially used as precursors for the preparation of $\mathrm{N}$-heterocyclic carbene (NHC) metal complexes in catalysis. ${ }^{12}$ 
In addition imidazolium containing systems are known as receptors for anion recognition. ${ }^{13}$ Recently, a few examples with $N$-carboxy-functionalized imidazolium salts have been employed in the synthesis of CPs. ${ }^{14}$ Very recently we have reported the synthesis of backbone thio-functionalized imidazolium salts and their metal complexes as well as the catalytic applications of palladium complexes in catalysis. ${ }^{15}$

Keeping these facts in mind we have designed a rigid ligand, 4,5-dicarboxy-1,3-dimethyl- $1 \mathrm{H}$-imidazolium iodide $\left(\mathrm{H}_{2} \mathrm{DDII}\right)$, containing a backbone functionalized imidazolium salt. The main interest behind the design of this ligand was to use it for the synthesis of metal carboxylate complexes/CPs and further use them as supports to incorporate catalytically active metal centers as well as to study the possible anion trapping inside the cavity. In this regard we have carried out the reaction of $\mathrm{H}_{2}$ DDII with $\left(n-\mathrm{Bu}_{3} \mathrm{Sn}\right)_{2} \mathrm{O}$ based on the versatile reactivity of organocarboxylic acids with tin(Iv) precursors and isolated a hexameric hexagonal organotin 42-membered macrocycle $\left[\left(n-\mathrm{Bu}_{3} \mathrm{Sn}\right)_{6}(\mu-\mathrm{L})_{6}\left(\mathrm{I}^{-}\right)_{2}(\mathrm{MeOH})_{6}\right]\left(\mathrm{L}=\mathrm{H}_{2} \mathrm{DDII}\right)$ with trapped iodide ions showing an interesting iodide-iodide short contact. ${ }^{16}$ However if the reactions are carried out with zinc(II) or cadmium(II) precursors, mono or dinuclear zinc complexes or CPs of zinc and cadmium were obtained which were highly influenced by the nature of the metal ion precursors, stoichiometry of the ligand and metal, type of base and solvent conditions. Herein, we report the syntheses and structural characterization of five metal complexes and/or CPS, namely, $\left[\mathrm{Zn}(\mathrm{Cl})\left(\mathrm{H}_{2} \mathrm{O}\right)_{2}(\mathrm{DDI})\right] \cdot \mathrm{H}_{2} \mathrm{O}(2), \quad\left\{\left[\mathrm{Zn}_{2}(\mathrm{DDI})_{3}\left(\mathrm{H}_{2} \mathrm{O}\right)_{2}\right] \cdot \mathrm{I}\right\}_{n}$ (3), $\left[\mathrm{Zn}_{2}(\mathrm{DDI})_{2} \mathrm{I}\right] \cdot 2 \mathrm{H}_{2} \mathrm{O}(4),\left[\mathrm{Zn}(\mathrm{DDI})_{2}\left(\mathrm{H}_{2} \mathrm{O}\right)_{3}\right] \cdot 2 \mathrm{H}_{2} \mathrm{O}(5)$ and $[\mathrm{Cd}-$ $\left.(\mathrm{DDI})_{2}\right]_{n}$ (6) whose structures range from discrete molecular units (monomer and dimer) to 2D CPs and are composed of an anionic zwitterion (DDI ${ }^{-}$). Besides, we also discuss the structural characterization of the zwitterion [HDDI (1)], obtained upon crystallization of $\mathrm{H}_{2}$ DDII, showing intra- as well as intermolecular $\mathrm{H}$-bonding in addition to the intermolecular $\mathrm{C}=\mathrm{O} \cdots \mathrm{C}$ short contact and resulting in a supramolecular helical 2D network structure. The structural properties of compounds 1-6 have been discussed along with infrared spectra (IR), powder X-ray diffraction (PXRD) and thermogravimetric analysis (TGA). In addition, the solid state fluorescence properties of $\mathrm{H}_{2}$ DDII and compounds 2-6 have been investigated.

\section{Experimental section}

\section{General details}

Anhyd. $\mathrm{ZnCl}_{2}$ and $\mathrm{Zn}\left(\mathrm{NO}_{3}\right)_{2} \cdot 6 \mathrm{H}_{2} \mathrm{O}$ were obtained from Alfa Aesar, while $\mathrm{Cd}\left(\mathrm{NO}_{3}\right)_{2} \cdot 4 \mathrm{H}_{2} \mathrm{O}$ was obtained from SD Fine, India. 4,5-Imidazoledicarboxylic acid was obtained from Sigma-Aldrich. All other chemicals were used without further purification. Solvents were first dried and then used after distillation. 4,5-Bis(ethoxycarbonyl)-1,3-dimethyl imidazolium iodide was prepared according to the reported literature procedure. ${ }^{17}$ Microanalyses for all the compounds were recorded using a Perkin Elmer Series-II CHNS/O model 2400 analyzer. IR spectra were recorded on a Bruker model vertex 70 and a
Perkin-Elmer model 1320 spectrometer using $\mathrm{KBr}$ pellets in the region of $4000-400 \mathrm{~cm}^{-1}$. Thermogravimetric analyses were carried out under $\mathrm{N}_{2}$ atmosphere with a heating rate of $10{ }^{\circ} \mathrm{C} \mathrm{min}^{-1}$ using a Mettler Toledo Star System. NMR spectra were recorded on a JEOL ECX-500. Powder X-ray Diffraction (PXRD) data were collected on a PANalytical X'Pert Pro X-ray diffractometer with $\mathrm{Cu} \mathrm{K \alpha}$ radiation $(\lambda=1.540598 \AA)$ at room temperature with a scan step size of 0.02 in $2 \theta$. Solid state emission spectra were recorded using a ZSX primus series spectrometer (Rigaku Corporation) at room temperature. DIAMOND (version 3.0) and Mercury (version 3) were used to view and draw the structures.

\section{4,5-Dicarboxy-1,3-dimethyl-1H-imidazolium iodide $\left(\mathrm{H}_{2} \mathrm{DDII}\right)$}

$\mathrm{H}_{2}$ DDII was prepared by the acid hydrolysis of 4,5-bis(ethoxycarbonyl)-1,3-dimethyl imidazolium iodide under reflux conditions for $12 \mathrm{~h}$ using $6 \mathrm{~N} \mathrm{HCl}$. A clear yellow solution was obtained, which was removed, and the resulting compound was washed with acetone followed by diethyl ether to obtain $\mathrm{H}_{2}$ DDII as a light grey compound. Yield: $40 \%$ (based on 4,5-imidazoledicarboxylic acid). Anal. calcd. for $\mathrm{C}_{7} \mathrm{H}_{9} \mathrm{~N}_{2} \mathrm{O}_{4} \mathrm{I}(312.06 \mathrm{~g}): \mathrm{C}, 26.94 ; \mathrm{H}, 2.91 ; \mathrm{N}, 8.98$. Found: $\mathrm{C}$, 26.80; H, 2.90; N, 8.92. IR (KBr, $\left.\mathrm{cm}^{-1}\right)$ : $3422(\mathrm{w}), 3145(\mathrm{~m})$, 3086 (m), 3010 (w), 2979 (w), 2709 (w), 1723 (vs), 1566 (vs), 1473 (vs), 1416 (s), 1370 (m), 1348 (s), 1352 (w), 1300 (s), 1245 (s), 1220 (s), 1144 (vs), 1091 (m), 894 (m), 869 (m), 826 (s), $762(\mathrm{~m}), 692(\mathrm{~s}), 629(\mathrm{~m}), 602(\mathrm{~m}), 482(\mathrm{~m}) .{ }^{1} \mathrm{H}$ NMR $(500$ $\mathrm{MHz}, \delta$-DMSO- $\left.d_{6}\right): 9.27(\mathrm{~s}, 1 \mathrm{H}, \mathrm{NCHN})$ and $3.96(\mathrm{~s}, 6 \mathrm{H}, 2$ $\left.\mathrm{NCH}_{3}\right) .{ }^{13} \mathrm{C}-\mathrm{NMR}\left(500 \mathrm{MHz}, \delta\right.$-DMSO- $\left.d_{6}\right) \delta 159.1$ (2C, C=O), $141.1(\mathrm{NCHN}), 129(2 \mathrm{C}, \mathrm{C}=\mathrm{C}), 37.7\left(2 \mathrm{C}, \mathrm{NCH}_{3}\right)$. ESI-MS (+ve) $185\left[(\mathrm{M}+\mathrm{H})^{+}, 100 \%\right]$ and ESI-MS (-ve) $126.90\left(\mathrm{I}^{-}\right)$.

HDDI (1). $\mathrm{H}_{2}$ DDII was dissolved in DMSO and layered with $\mathrm{MeOH}$. Yellow crystals were obtained after one week. Yield: $63 \%$ (based on $\mathrm{H}_{2}$ DDII). Anal. calcd. for $\mathrm{C}_{7} \mathrm{H}_{8} \mathrm{~N}_{2} \mathrm{O}_{4}$ (184.15 g): C, 45.66; H, 4.38; N, 15.21. Found: C, 45.65; H, 4.30; N, 15.14. IR (KBr, cm $\left.{ }^{-1}\right): 3419$ (w), 3139 (w), 3060 (m), 1728 (m), 1573 (vs), 1470 (vs), 1432 (s), 1397 (s), 1371 (s), 1303 (s), 1178 (m), 1024 (m), 907 (w), 869 (w), 833 (w), 770 (m), 657 (br), 629 (m), 600 (w), 498 (w). ${ }^{1} \mathrm{H}$ NMR (500 MHz, DMSO- $\left.d_{6}\right): \delta 9.23(\mathrm{~s}, 1 \mathrm{H}, \mathrm{NCHN})$ and $3.97\left(\mathrm{~s}, 6 \mathrm{H}, 2 \mathrm{NCH}_{3}\right)$. ${ }^{13} \mathrm{C}-\mathrm{NMR}\left(500 \mathrm{MHz}, \delta\right.$-DMSO- $\left.d_{6}\right) 159.1$ (2C, C=O), 141.1 ( $\mathrm{NCHN}), 129.1$ (2C, C=C), $37.6\left(2 \mathrm{C}, \mathrm{NCH}_{3}\right)$. ESI-MS (+ve) 185 $\left[(\mathrm{M}+\mathrm{H})^{+}, 100 \%\right]$.

$\left[\mathrm{Zn}(\mathrm{Cl})\left(\mathrm{H}_{2} \mathrm{O}\right)_{2}(\mathrm{DDI})\right] \cdot \mathrm{H}_{2} \mathrm{O}(2)$. Aq. $\mathrm{NH}_{3}(0.1 \mathrm{~mL})$ was added to a solution of $\mathrm{H}_{2}$ DDII $(46.6 \mathrm{mg}, 0.15 \mathrm{mmol})$ in $\mathrm{CH}_{3} \mathrm{OH}(10$ $\mathrm{mL}$ ) followed by addition of anhyd. $\mathrm{ZnCl}_{2}(20.4 \mathrm{mg}, 0.15$ $\mathrm{mmol}$ ) and the solution was stirred for $30 \mathrm{~min}$. The solution was allowed to evaporate at room temperature very slowly to afford pale yellow crystals after one day. Yield: $90.2 \mathrm{mg}(60 \%$ based on anhyd. $\mathrm{ZnCl}_{2}$ ). Anal. calcd. for $\mathrm{C}_{7} \mathrm{H}_{13} \mathrm{~N}_{2} \mathrm{O}_{7} \mathrm{ClZn}$ (338.03 g): C, 24.87; H, 3.88; N, 8.29. Found: C, 24.83; H, 3.84; N, 8.26. IR (KBr, $\mathrm{cm}^{-1}$ ): 3425 (s), 3335 (vs), $3128(\mathrm{~m})$, 3059 (s), 1640 (vs), 1559 (vs), 1474 (s), 1450 (m), 1407 (vs), 1373 (s), 1348 (s), 1321 (vs), 1271 (vs), 1220 (s), 1168 (vs), 899 (s), $880(\mathrm{w}), 826(\mathrm{~s}), 802(\mathrm{~m}), 723(\mathrm{~m}), 698(\mathrm{~m}), 632(\mathrm{~s}), 617$ (s), $474(\mathrm{~s})$. 
Synthesis of $\left\{\left[\mathrm{Zn}_{2}(\mathrm{DDI})_{3}\left(\mathrm{H}_{2} \mathrm{O}\right)_{2}\right] \cdot \mathrm{I}\right\}_{n}$ (3). Aq. $\mathrm{NH}_{3}(0.2 \mathrm{~mL})$ was added to a solution of $\mathrm{H}_{2}$ DDII $(93.2 \mathrm{mg}, 0.3 \mathrm{mmol})$ in $\mathrm{CH}_{3} \mathrm{OH}(20 \mathrm{~mL})$ followed by addition of $\mathrm{ZnCl}_{2}(20.4 \mathrm{mg}$, $0.15 \mathrm{mmol}$ ) as solid. The solution was refluxed for $2 \mathrm{~h}$ and allowed to cool to room temperature. Colorless crystals of 3 were obtained after two days by slow evaporation of the solution at room temperature. Yield: $57 \mathrm{mg}$ (91\% based on $\left.\mathrm{ZnCl}_{2}\right)$. Anal. calcd. for $\mathrm{C}_{21} \mathrm{H}_{25} \mathrm{~N}_{6} \mathrm{O}_{14} \mathrm{IZn}_{2}$ (843.15 g): C, 29.91; H, 2.99; $\mathrm{N}$, 9.97. Found: C, 29.90; H, 2.96; N, 9.95. IR (KBr, $\left.\mathrm{cm}^{-1}\right): 3325$ (m), 3149 (m), 3073 (m), 1644 (vs), 1566 (vs), 1485 (m), 1411 (vs), 1383 (vs), 1348 (vs), 1327 (vs), 1174 (vs), 903 (m), 834 (m), $790(\mathrm{~m}), 748(\mathrm{~m}), 666(\mathrm{~m}), 634(\mathrm{~m}), 589(\mathrm{w}), 501(\mathrm{w}), 459(\mathrm{w})$.

$\left[\mathrm{Zn}_{2}(\mathrm{DDI})_{2} \mathrm{I}\right] \cdot 2 \mathrm{H}_{2} \mathrm{O}$ (4). Aq. $\mathrm{NH}_{3}(0.2 \mathrm{~mL})$ was added to a solution of $\mathrm{H}_{2}$ DDII $(93.2 \mathrm{mg}, 0.3 \mathrm{mmol})$ in $\mathrm{CH}_{3} \mathrm{OH}(10 \mathrm{~mL})$ followed by addition of $\mathrm{Zn}\left(\mathrm{NO}_{3}\right)_{2} \cdot 6 \mathrm{H}_{2} \mathrm{O}(37.1 \mathrm{mg}, 0.125 \mathrm{mmol})$. The solution was refluxed for $2 \mathrm{~h}$ and allowed to cool to room temperature. Colorless crystals of 4 were obtained after two days by slow evaporation of the solution at room temperature. Yield: $35.1 \mathrm{mg}$ ( $85 \%$ based on $\left.\mathrm{Zn}\left(\mathrm{NO}_{3}\right)_{2} \cdot 6 \mathrm{H}_{2} \mathrm{O}\right)$. Anal. calcd. for $\mathrm{C}_{14} \mathrm{H}_{18} \mathrm{~N}_{4} \mathrm{O}_{10} \mathrm{IZn}_{2}$ (659.96 g): C, 32.27; $\mathrm{H}, 3.63 ; \mathrm{N}$, 13.72. Found: C, 32.24; H, 3.60; N, 13.69. IR (KBr, $\left.\mathrm{cm}^{-1}\right): 3436$ (b), 3138 (m), 3064 (s), 2969 (br), 2925 (br), 1733 (m), 1565 (vs), 1470 (vs), 1432 (s), 1414 (m), 1396 (s), 1370 (s), 1300 (vs), 1176 (s), 1090 (s), 910 (w), 869 (m), 838 (m), 770 (s), 680 (w), $629(\mathrm{~s}), 605(\mathrm{w}), 497(\mathrm{~m})$.

Synthesis of $\left[\mathrm{Zn}(\mathrm{DDI})_{2}\left(\mathrm{H}_{2} \mathrm{O}\right)_{3}\right] \cdot 2 \mathrm{H}_{2} \mathrm{O}(5)$. Triethylamine $(0.2$ $\mathrm{mL}$ ) was added to a solution of $\mathrm{H}_{2} \mathrm{DDII}(62.2 \mathrm{mg}, 0.2 \mathrm{mmol})$ in $\mathrm{CH}_{3} \mathrm{CN} / \mathrm{H}_{2} \mathrm{O}(6: 8 \mathrm{~mL})$ followed by addition of $\mathrm{Zn}\left(\mathrm{NO}_{3}\right)_{2} \cdot 6 \mathrm{H}_{2} \mathrm{O}(59.4 \mathrm{mg}, 0.2 \mathrm{mmol})$ as solid. The solution was refluxed for $15 \mathrm{~h}$ and allowed to cool to room temperature. The solution was allowed to evaporate at room temperature very slowly to afford colorless crystals of $\mathbf{5}$ after twentyfive days. Yield: $50 \mathrm{mg}$ ( $25 \%$ based on $\left.\mathrm{Zn}\left(\mathrm{NO}_{3}\right)_{2} \cdot 6 \mathrm{H}_{2} \mathrm{O}\right)$. Anal. calcd. for $\mathrm{C}_{14} \mathrm{H}_{24} \mathrm{~N}_{4} \mathrm{O}_{13} \mathrm{Zn}(521.76 \mathrm{~g})$ : $\mathrm{C}, 32.23 ; \mathrm{H}, 4.64 ; \mathrm{N}$, 10.74. Found: $\mathrm{C}, 32.22 ; \mathrm{H}, 4.64 ; \mathrm{N}, 10.71$. IR $\left(\mathrm{KBr}, \mathrm{cm}^{-1}\right): 3414$ (m), 3149 (w), 3048 (m), 1630 (vs), 1611 (vs), 1570 (vs), 1474 (s), 1404 (s), 1375 (vs), 1313 (s), 1230 (w), 1175 (s), 1090 (w), $1034(\mathrm{w}), 894(\mathrm{w}), 827(\mathrm{~m}), 789(\mathrm{w}), 765$ (m), $745(\mathrm{w}), 626(\mathrm{~m})$, 599 (m), 487 (w), 435 (br), 405 (br).
Synthesis of $\left[\mathrm{Cd}(\mathrm{DDI})_{2}\right]_{n}$ (6). A similar synthetic procedure to that of 5 was performed except that $\mathrm{Cd}\left(\mathrm{NO}_{3}\right)_{2} \cdot 4 \mathrm{H}_{2} \mathrm{O}$ $(61.6 \mathrm{mg}, 0.2 \mathrm{mmol})$ was used instead of $\mathrm{Zn}\left(\mathrm{NO}_{3}\right)_{2} \cdot 6 \mathrm{H}_{2} \mathrm{O}$. Colorless crystals of 6 were formed after thirty days. Yield: $10 \mathrm{mg}$ $\left(17 \%\right.$ based on $\left.\mathrm{Cd}\left(\mathrm{NO}_{3}\right)_{2} \cdot 4 \mathrm{H}_{2} \mathrm{O}\right)$. Anal. calcd. for $\mathrm{C}_{14} \mathrm{H}_{14} \mathrm{~N}_{4} \mathrm{O}_{8} \mathrm{Cd}$ (478.69 g): C, 35.13; H, 2.95; N, 11.70. Found: C, 35.11; H, 2.92; N, 11.65. IR (KBr, $\left.\mathrm{cm}^{-1}\right)$ : IR $\left(\mathrm{KBr}, \mathrm{cm}^{-1}\right)$ : $3411(\mathrm{w})$, 3149 (w), 3085 (m), 1626 (vs), 1607 (vs), 1567 (vs), 1476 (s), 1406 (vs), 1383 (vs), 1357 (s), 1328 (s), 1220 (w), 1175 (s), $1091(\mathrm{w}), 903(\mathrm{~m}), 874(\mathrm{w}), 839(\mathrm{~m}), 796(\mathrm{~m}), 764(\mathrm{w})$, $741(\mathrm{~m}), 617(\mathrm{~m}), 575(\mathrm{w}), 477(\mathrm{w})$.

\section{X-ray crystallography}

Single crystal X-ray data for 1-6 were collected at $100 \mathrm{~K}(1-4)$ and $293 \mathrm{~K}$ (5-6) on a Bruker SMART APEX CCD diffractometer using graphite monochromated MoK $\alpha$ radiation $(\lambda=$ $0.71073 \AA$ A). All the structures were solved using SHELXS-97 and refined by full-matrix least squares on $F^{2}$ using SHELXL-97. ${ }^{18}$ All hydrogen atoms were included in idealized positions using a riding model. Non-hydrogen atoms were refined with anisotropic displacement parameters. Topological analysis of CPs 3 and 6 was performed using the ADS program of the TOPOS 4.0 Professional structuretopological program package. ${ }^{19}$

\section{Results and discussion}

\section{4,5-Dicarboxy-1,3-dimethyl-1H-imidazolium iodide ( $\left.\mathrm{H}_{2} \mathrm{DDII}\right)$}

$\mathrm{H}_{2}$ DDII was prepared through a stepwise procedure. Firstly, 4,5-bis(ethoxycarbonyl)-1,3-dimethyl imidazolium iodide was synthesized according to a literature procedure through multi-step synthesis (Scheme 1). It was followed by the hydrolysis of 4,5-bis(ethoxycarbonyl)-1,3-dimethyl imidazolium iodide using $6 \mathrm{~N} \mathrm{HCl}$, resulting in the formation of ligand $\mathrm{H}_{2}$ DDII which was obtained as a grey compound in moderate yield. The formation of $\mathrm{H}_{2}$ DDII was confirmed by spectroscopic and spectrometric techniques and it was found to be

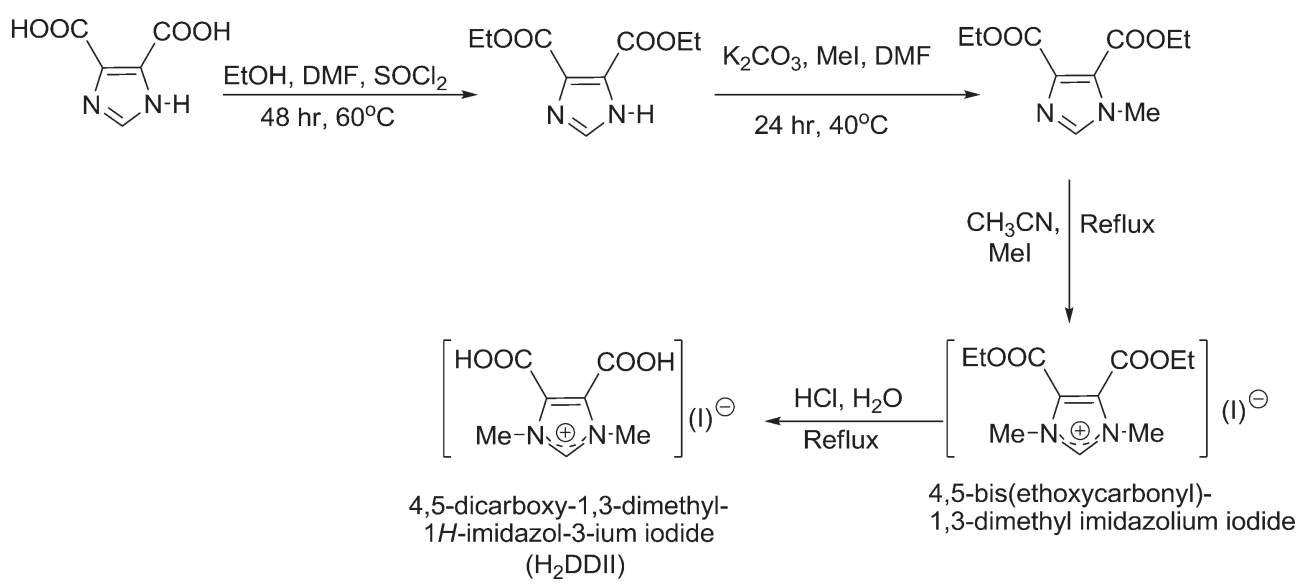

Scheme 1 Synthesis of $\mathrm{H}_{2}$ DDII. 
soluble in DMSO, DMF and MeOH. The complete hydrolysis of 4,5-bis(ethoxycarbonyl)-1,3-dimethyl imidazolium iodide to $\mathrm{H}_{2}$ DDII was confirmed through ${ }^{1} \mathrm{H}-\mathrm{NMR}$ as indicated by the absence of $\mathrm{COOCH}_{2} \mathrm{CH}_{3}$ protons and also by the shielding effect observed for $\mathrm{NCHN}[9.41(\mathrm{~s}, 1 \mathrm{H})]$ and the slight deshielding effect observed for $\mathrm{NCH}_{3}[3.90$ (s, 6H)] (Fig. S1-S2).

As it was observed in $N$-carboxy functionalized imidazolium salts, $\mathrm{H}_{2}$ DDII is expected to form a zwitterion [HDDI (1)] or an anionic zwitterion (DDI ${ }^{-}$) (Scheme 2) in solution. HDDI could possibly coordinate to the metal through one or two oxygen atoms of the deprotonated carboxylate moiety, whereas $\mathrm{DDI}^{-}$has four carboxylate O-donor atoms which can possibly coordinate to the metal centers in various fashions such as monodentate terminal/bridging, bidentate chelate/ bridging or chelate-bridging ${ }^{20}$ (Scheme 3), resulting in structures having an anionic zwitterion with different topologies.

Interestingly, $\mathrm{H}_{2}$ DDII upon crystallization in DMSO and methanol formed HDDI (1), which was characterized by IR, NMR, ESI-MS and single crystal X-ray diffraction methods (Fig. S3-S4). 1 crystallizes in the monoclinic system with the space group $P 2_{1} / n$ (Table 1 ) and was found to have a zwitterionic structure with the loss of HI (Fig. 1a) in solution. In 1, an intramolecular $\mathrm{H}$-bond exists between $\mathrm{O} 2 \cdots \mathrm{H} 3-\mathrm{O} 3$, arising from the carboxylate units, with a distance of 1.587(2) (Fig. 1b). ${ }^{21}$ In addition, intermolecular $\mathrm{O} \cdots \mathrm{H}-\mathrm{C}$ interactions ${ }^{22}$ exist between $\mathrm{O} 1 \cdots \mathrm{H} 1{ }^{*}-\mathrm{C} 1$ as well as $\mathrm{O} 2 \cdots \mathrm{H} 1-\mathrm{C} 1$ with adjacent

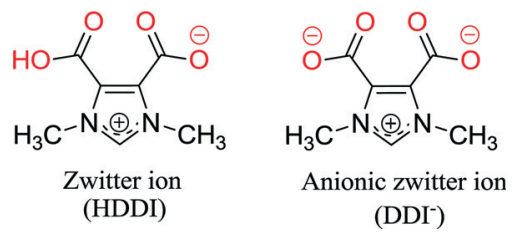

Scheme 2 Deprotonated forms of $\mathrm{H}_{2} \mathrm{DDI}$.
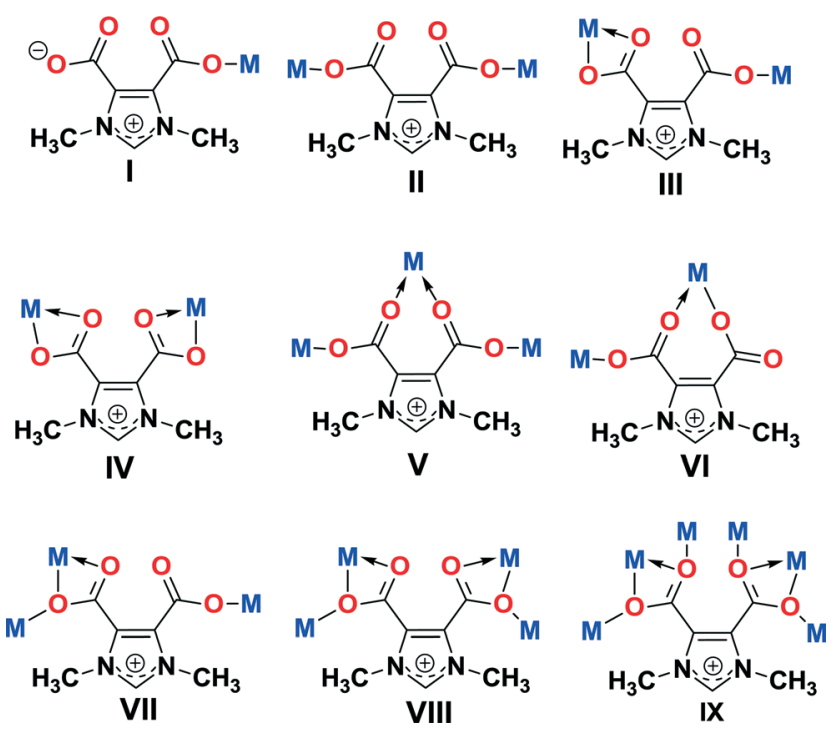

Scheme 3 Possible coordination modes of the anionic zwitterion (DDI').
HDDI units, while $\mathrm{O} 4 \cdots \mathrm{H} 6 \mathrm{CH}-\mathrm{C} 6$ interactions were present between the stacked up HDDI units, one over the other layers (Fig. 1b, Table 3). Besides, there also exists an interesting intermolecular $\mathrm{C}=\mathrm{O} \cdots \mathrm{C}$ short contact between $\mathrm{C} 5=\mathrm{O} 4 \cdots \mathrm{C} 1$ \$ having a distance of $2.895(3) \AA$ and connecting two adjacent HDDI units (Fig. 1c, Table 3). ${ }^{23}$ These interactions collectively tend to form perpendicular adjacent layers of HDDI and also stack up one HDDI unit over the other, leading to an extended supramolecular helical 2D network structure (Fig. 1d).

\section{Syntheses of 2-6}

The coordination ability of $\mathrm{H}_{2}$ DDII with the metal ions was evaluated by the synthesis of complexes of $\mathrm{Zn}$ (II) and $\mathrm{Cd}(\mathrm{II})$ using a simple evaporation technique. The removal of the carboxylic acid proton from $\mathrm{H}_{2}$ DDII was facilitated by the use of aq. $\mathrm{NH}_{3}$ and $\mathrm{Et}_{3} \mathrm{~N}$ as base. In these reactions, the $\mathrm{pH}$ of the solution was maintained always between 8 and 9. The syntheses of complexes 2-4 were accomplished by using $\mathrm{ZnCl}_{2}$ (2 and 3) and $\mathrm{Zn}\left(\mathrm{NO}_{3}\right)_{2} \cdot 6 \mathrm{H}_{2} \mathrm{O}$ (4) as metal precursors and aq. $\mathrm{NH}_{3}$ as base in methanol (Scheme 4). The stoichiometry of the metal and ligand plays an important role in determining the structure of the resulting products. The stoichiometric ratio of $\mathrm{ZnCl}_{2}$ to $\mathrm{H}_{2}$ DDII of $1: 1$ and $1: 2$ yields 2 and 3 , respectively. The same synthetic conditions as those for 2 and 3 were followed for the preparation of 4 , except that $\mathrm{Zn}\left(\mathrm{NO}_{3}\right)_{2} \cdot 6 \mathrm{H}_{2} \mathrm{O}$ was used in the reaction, whereas the syntheses of 5 and 6 were carried out using a strong base and $\mathrm{M}\left(\mathrm{NO}_{3}\right)_{2} \cdot x \mathrm{H}_{2} \mathrm{O}(\mathrm{M}=\mathrm{Zn}(5), x=6 ; \mathrm{M}=\mathrm{Cd}(6), x=4)$ in $\mathrm{CH}_{3} \mathrm{CN} / \mathrm{H}_{2} \mathrm{O}$ medium (Scheme 4 ). All the products (2-6) were insoluble in common organic solvents. The IR spectra of 2-6 showed stretching frequencies for $v_{\mathrm{as}}(\mathrm{COO})$ and $v_{\mathrm{s}}$ (COO) around $1600 \mathrm{~cm}^{-1}$ and $1400-1300 \mathrm{~cm}^{-1}$, respectively, which support the binding of carboxylate to the metal ion. Further, the absence of strong IR bands around $1700 \mathrm{~cm}^{-1}$ in $2-6$ and the presence of multiple stretching frequency peaks in the region of metal carboxylates suggest variable binding modes of carboxylate units to metal ions. To understand better the product formation and the details of the final structures of products 2-6, a single crystal X-ray diffraction study was carried out.

\section{Solid state structures of 2-6}

$\left[\mathrm{Zn}(\mathrm{Cl})\left(\mathrm{H}_{2} \mathrm{O}\right)_{2}(\mathrm{DDI})\right] \cdot \mathrm{H}_{2} \mathrm{O}$ (2). Single crystal X-ray diffraction studies shows that 2 crystallizes in the monoclinic space group $P 2_{1} / n$ (Table 1 ). It consists of a $\mathrm{Zn}$ (II) ion, one $\mathrm{DDI}^{-}$ unit, one $\mathrm{Cl}^{-}$ion and two coordinated $\mathrm{H}_{2} \mathrm{O}$ molecules along with one $\mathrm{H}_{2} \mathrm{O}$ molecule as water of crystallization. The $\mathrm{Zn}$ (II) ion lies in a tetrahedral environment and is coordinated by one donor oxygen atom provided by the $\mathrm{DDI}^{-}$unit and one chloride ion, while the remaining two sites are occupied by two $\mathrm{H}_{2} \mathrm{O}$ molecules (Fig. 2a). In 2, both the hydrogen atoms from carboxylates along with the iodide ion are eliminated. The O-atom from the carboxylate unit of $\mathrm{DDI}^{-}$coordinates to $\mathrm{Zn}$ (II) in monodentate terminal mode (I; Scheme 3), while the 
Table 1 Crystallographic data and structural refinements for 1-6

\begin{tabular}{|c|c|c|c|c|c|c|}
\hline & 1 & 2 & 3 & 4 & 5 & 6 \\
\hline Fw & 184.15 & 338.01 & 843.11 & 659.96 & 521.74 & 478.69 \\
\hline Crystal system & Monoclinic & Monoclinic & Orthorhombic & Triclinic & Monoclinic & Monoclinic \\
\hline$a(\AA)$ & $7.052(2)$ & $8.4910(17)$ & $22.552(5)$ & $7.9324(13)$ & $15.075(2)$ & $8.8373(8)$ \\
\hline$b(\AA)$ & $8.324(3)$ & $8.0410(16)$ & $10.123(2)$ & $8.4897(14)$ & $8.3079(12)$ & $13.3995(8)$ \\
\hline$c(\AA)$ & $13.410(4)$ & $18.847(4)$ & $13.594(3)$ & $10.8444(18)$ & $16.676(3)$ & $13.4110(10)$ \\
\hline$\gamma(\mathrm{deg})$ & 90 & 90 & 90 & $64.679(2)$ & 90 & 90 \\
\hline$V\left(\AA^{3}\right)$ & $769.1(4)$ & $1262.5(4)$ & $3103.4(1)$ & $628.8(2)$ & $2086.1(5)$ & $1587.2(2)$ \\
\hline$Z$ & 4 & 4 & 4 & 1 & 4 & 4 \\
\hline$\rho_{\text {calc }}\left(\mathrm{g} \mathrm{cm}^{-3}\right)$ & 1.590 & 1.778 & 1.804 & 1.743 & 1.661 & 2.003 \\
\hline$\mu / \mathrm{mm}^{-1}$ & 0.132 & 2.184 & 2.614 & 3.185 & 1.253 & 1.434 \\
\hline$F(000)$ & 384 & 688 & 1672 & 323 & 1080 & 952 \\
\hline GOF on $F^{2}$ & 1.165 & 1.071 & 1.035 & 1.091 & 1.143 & 1.252 \\
\hline$R_{\text {int }}$ & 0.0368 & 0.0460 & 0.0590 & 0.0189 & 0.0464 & 0.0311 \\
\hline$R_{1} ; \mathrm{w} R_{2}[I>2 \sigma(I)]$ & $0.0486 ; 0.1357$ & $0.0397 ; 0.1079$ & $0.0527 ; 0.1418$ & $0.0534 ; 0.1627$ & $0.0516 ; 0.1324$ & $0.0316 ; 0.0752$ \\
\hline$R_{1} ; \mathrm{w} R_{2}$ (all data) & $0.0602 ; 0.1669$ & $0.0455 ; 0.1135$ & $0.0683 ; 0.1576$ & $0.0595 ; 0.1792$ & $0.0713 ; 0.1726$ & $0.0366 ; 0.1078$ \\
\hline
\end{tabular}

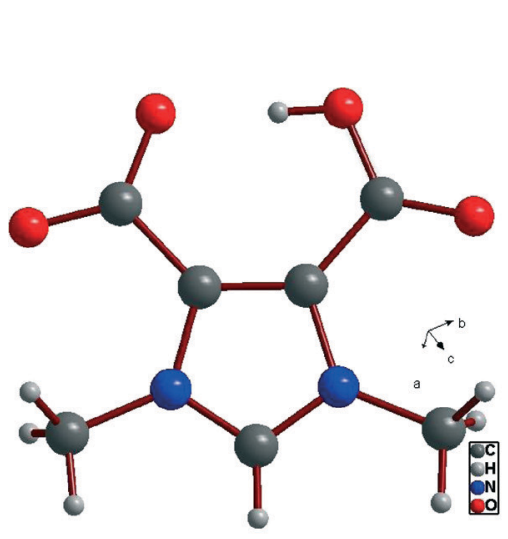

(a)

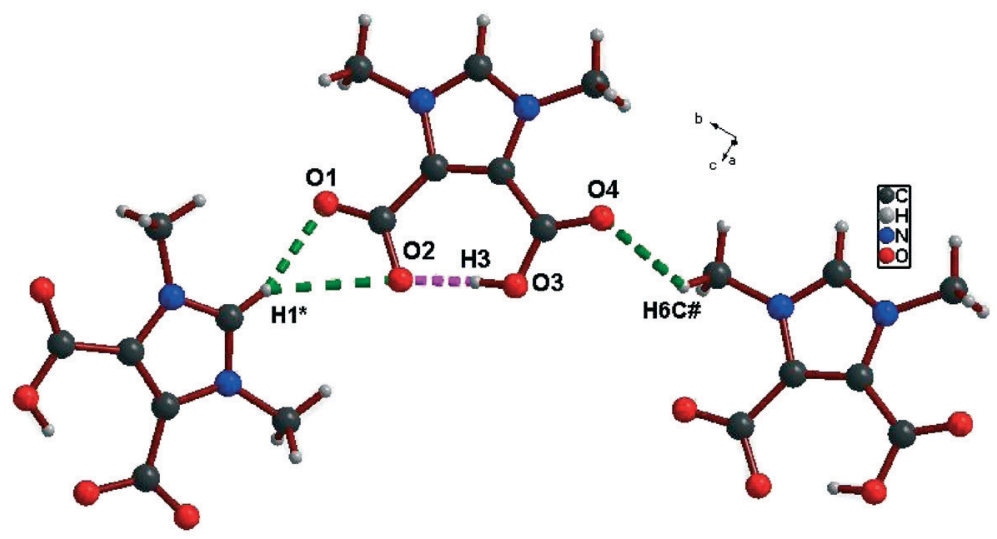

(b)

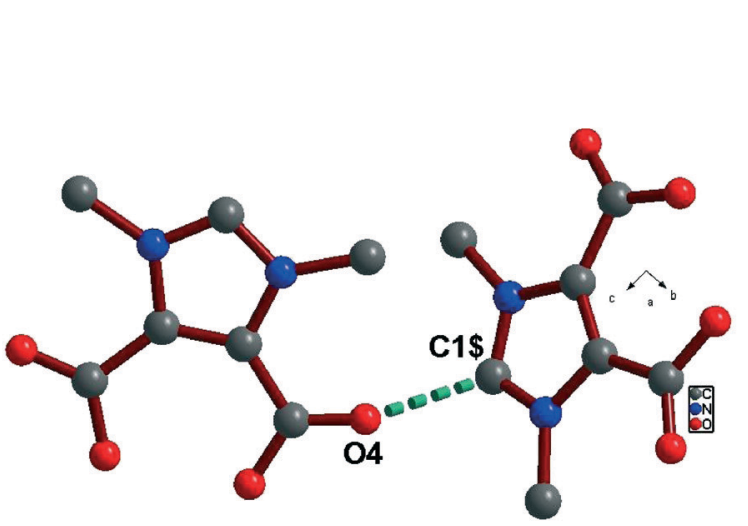

(c)

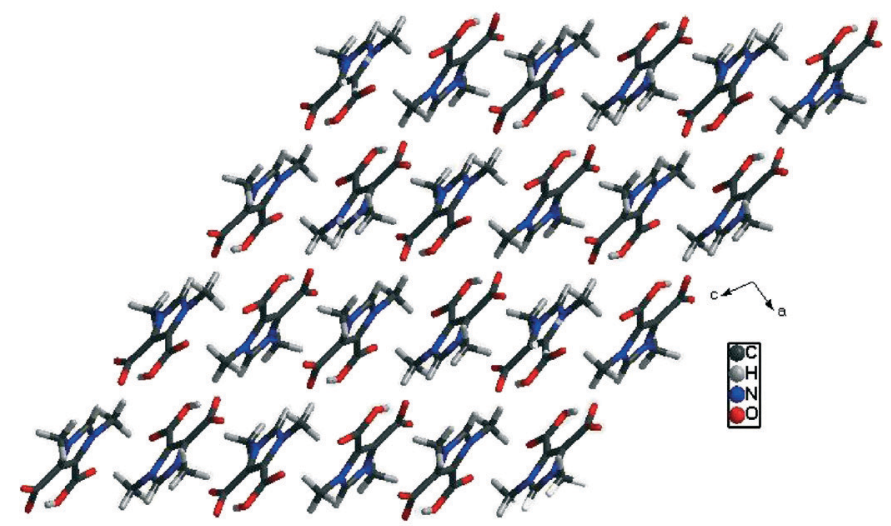

(d)

Fig. 1 (a) The zwitterionic structure of 1. (b) Inter-(green color) and intramolecular (pink color) $\mathrm{H}$-bonding interactions in 1. (c) Intermolecular $\mathrm{C}=\mathrm{O} \cdots \mathrm{C}$ short contact in 1. (d) Extended supramolecular architecture of 1 . [H1* is at $-1 / 2+x, 1 / 2-y,-1 / 2+z ; \mathrm{H} 6 \mathrm{C} \#$ is at $x, 1+y, z ; \mathrm{C} 1 \$$ is at $1 / 2-x, 1 / 2+y, 1 / 2+z]$. 

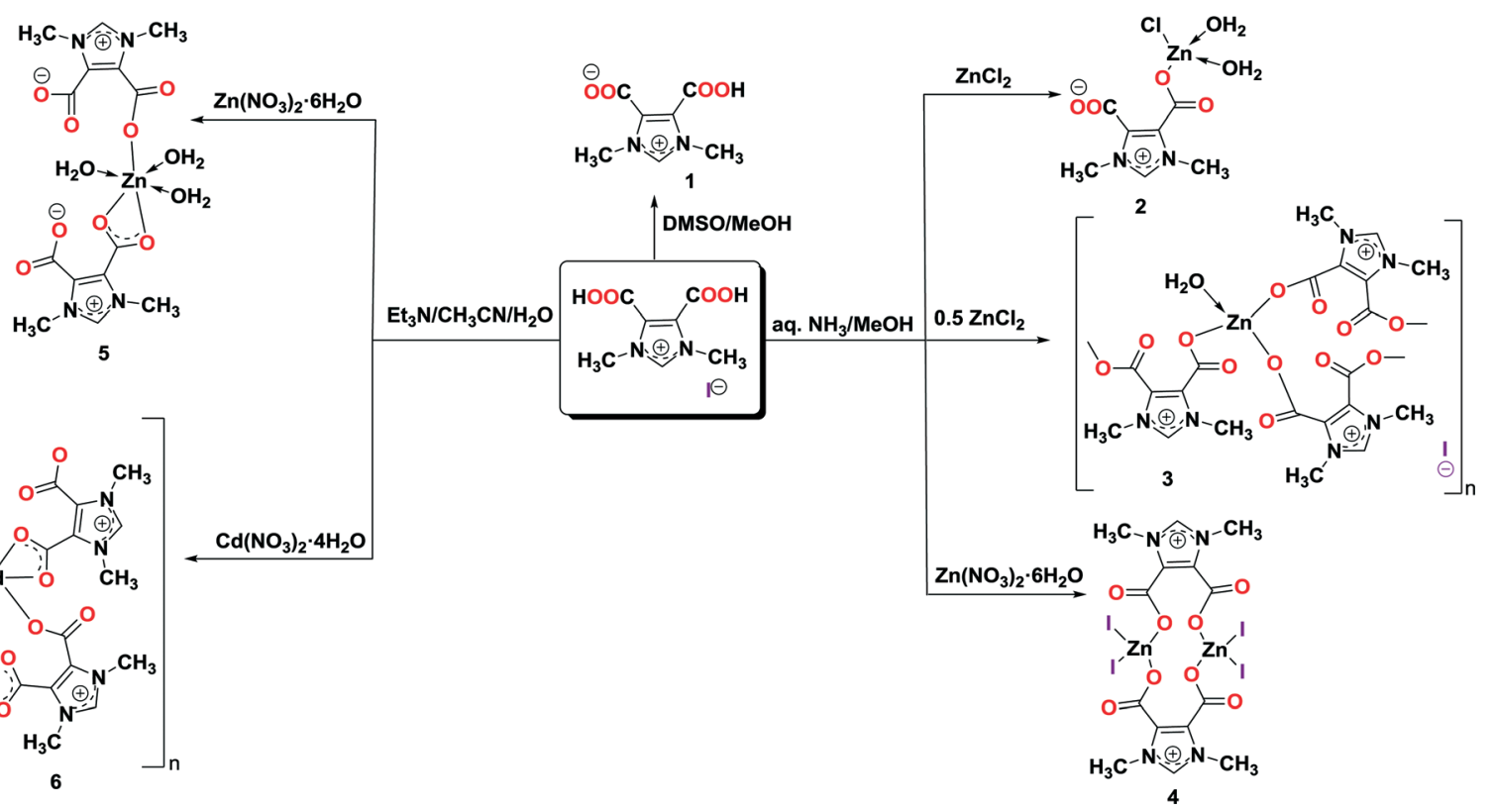

Scheme 4 Synthetic scheme and structures of 1-6.

second carboxylate unit has a free oxygen-donor site. Hence, the charge is balanced since one of the carboxylate groups remains uncoordinated. Thus, 2 can be described as an anionic zwitterion zinc complex as it was also observed in $N$-carboxy imidazolium metal dicarboxylates. ${ }^{14}$

The $\mathrm{Zn}-\mathrm{O}$ bond distance of carboxylate oxygen to zinc in 2 is found to be 2.009(4) $\AA$ (Zn-O1), comparable to the bond lengths reported with such a ligand system, ${ }^{9 h}$ whereas those for the water molecules coordinated to the $\mathrm{Zn}$ (II) ion are nearly the same [av. 2.001(3) $\AA$ ], while the bond distance of $\mathrm{Zn}-\mathrm{Cl}$ is 2.274(11) $\AA$ (Table 2). The asymmetric unit of 2 extends further through the $\mathrm{H}$-bonding existing between the chloride ion and $\mathrm{H}_{7} \mathrm{C}^{*}$ (from $\mathrm{N}-\mathrm{CH}_{3}$ ) and $\mathrm{H} 66$ \# (from $\mathrm{H}_{2} \mathrm{O}$ ) (Fig. 2b, Table 3) to form a 2D rectangular sheet (Fig. 2c and d). Each rectangular sheet comprises four monomeric units of 2 in which the two $\mathrm{DDI}^{-}$units are involved in facilitating the extended structure formation. The orientation of $\mathrm{DDI}^{-}$ (along $a$-axis) within the rectangular sheet and in the 2D layers is anti-parallel to each other. The chloride ions are oriented in opposite directions between two layers, but are in the same direction to the ones adjacent to it. The orientations of $\mathrm{DDI}^{-}$and $\mathrm{Cl}^{-}$ions play a significant role in extending the monomer through H-bonding. The distances between $\mathrm{Zn}$ (II) ions in such a rectangular sheet were found to be

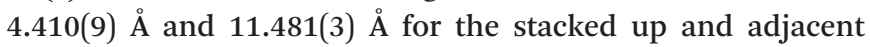
one, respectively (Fig. S5). The $2 \mathrm{D}$ rectangular sheets are further connected via the lattice water molecules which tend to act as a bridge through $\mathrm{CH}^{\cdots} \mathrm{O}$ interactions, (Table 3, Fig. S6), leading to the formation of a 3D supramolecular architecture (Fig. S7).

$\left\{\left[\mathrm{Zn}_{2}(\mathrm{DDI})_{3}\left(\mathrm{H}_{2} \mathrm{O}\right)_{2}\right] \cdot \mathbf{I}\right\}_{n}$ (3). Single crystal X-ray diffraction studies show that 3 crystallizes in the orthorhombic space group Pccn (Table 1). The analysis of the crystal structure reveals that 3 is an anionic zwitterion $2 \mathrm{D}$ CP with a basic unit composed of two zinc, three $\mathrm{DDI}^{-}$units, two water molecules and an iodide as a counter anion, with a 2 -fold imposed symmetry where the $\mathrm{C} 10-\mathrm{H} 10$ bond and I1 lie on different 2 -fold axes. Each $\mathrm{Zn}$ (II) ion lies in a tetrahedral environment and is coordinated by three donor oxygen-atoms provided by three individual $\mathrm{DDI}^{-}$units and one $\mathrm{H}_{2} \mathrm{O}$ molecule occupies the fourth coordination site (Fig. 3a). All the three oxygen atoms of $\mathrm{DDI}^{-}$coordinate to the $\mathrm{Zn}$ (II) ion in monodentate terminal mode (II; Scheme 3). The $\mathrm{Zn}-\mathrm{O}$ bond distance in 3 of carboxylate oxygen atoms to zinc falls in the range of 1.985(3) $\AA$ to 2.041(5) $\AA$ and this is consistent with the already reported values in the literature, ${ }^{9 h}$ while the bond angles around zinc vary from $95.76(14)^{\circ}$ to $123.10(17)^{\circ}$, hence the geometry of zinc can be described as a distorted tetrahedron (Table 2). In 3, the oxygen atoms from the second carboxylate unit of $\mathrm{DDI}^{-}$bind to the other zinc atoms to form a hexameric 42-membered crown-shaped macrocycle ring (Fig. 3b). The macrocycle consists of six $\mathrm{Zn}$ (II) atoms which are connected through six $\mathrm{DDI}^{-}$in the same direction while the other two (breadthwise) are in the opposite direction and hence form the crown shape of the macrocycle. Further, the O-atoms of the other carboxylate group of $\mathrm{DDI}^{-}$ units from the hexamer coordinate to another Zn(II) ion, which extends to form a 2D anionic zwitterion zinc CP with a herringbone network (Fig. 3c). Through topological analysis, 3 can be represented as a $6^{3}$ hcb topology with the $\mathrm{Zn}$ centre as a 3-connected uninodal net (Fig. 3d). The iodide ions in $\mathbf{3}$ are trapped inside the quasi hydrophilic channels of the $\mathrm{CP}$ and are involved in the $\mathrm{H}$-bonding between $\mathrm{I} 1 \# \cdots \mathrm{H}$ 9B (from $\mathrm{N}-\mathrm{CH}_{3}$ ) and $\mathrm{I} 1 \# \cdots \mathrm{H} 15$ (from $\mathrm{H}_{2} \mathrm{O}$ ) (Fig. 3e, Table 3). The 2D CP is further connected through an interlayer $\mathrm{CH} \cdots \mathrm{O}$ interaction between $\mathrm{CH}_{3}$ and $\mathrm{CH}$ of imidazolium units resulting in the formation of a 3D supramolecular network (Fig. 3f). 


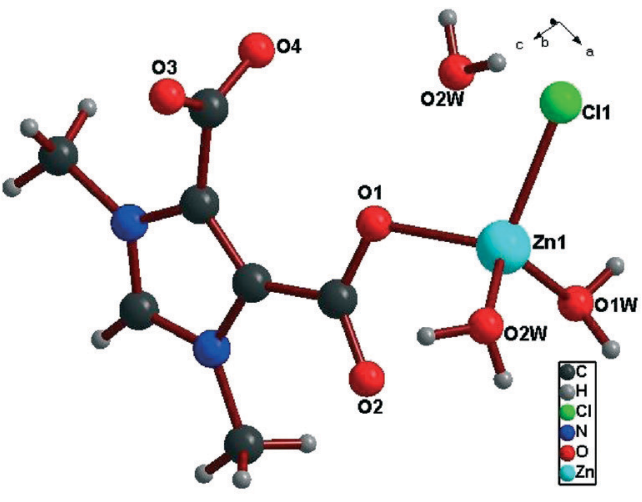

(a)

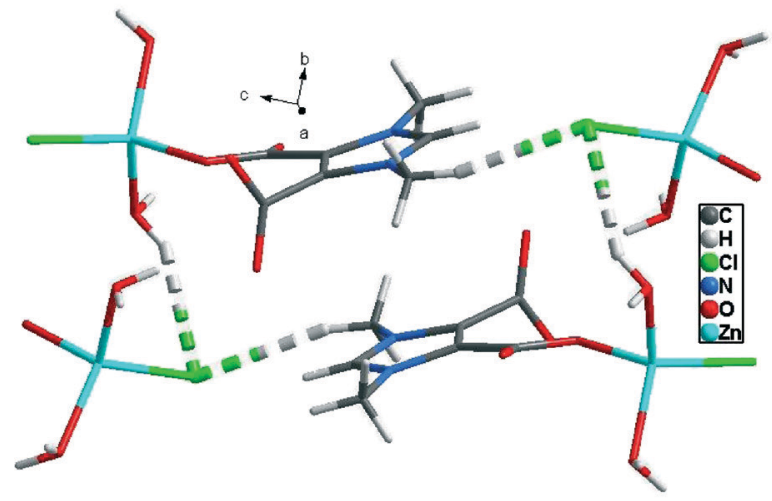

(c)

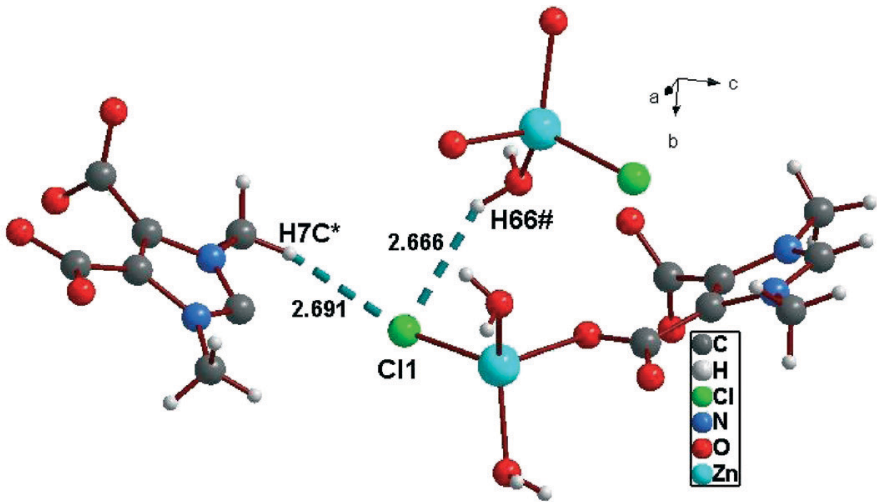

(b)

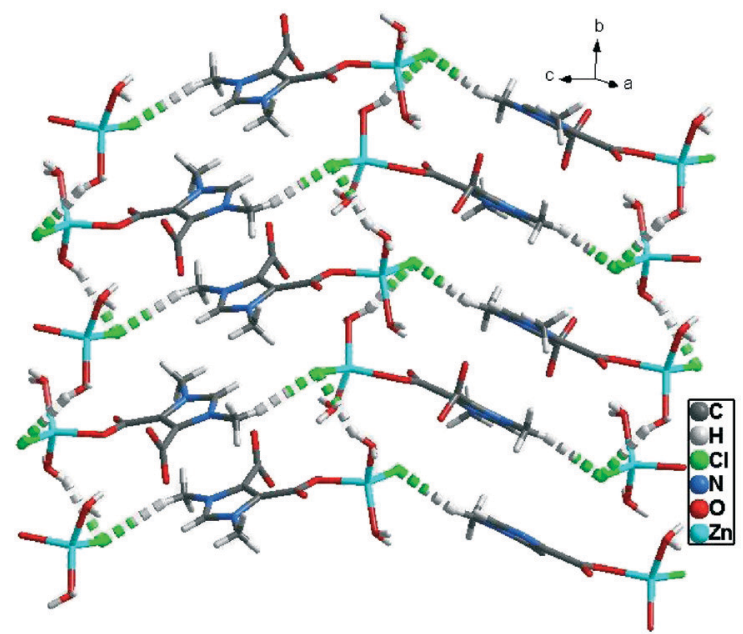

(d)

Fig. 2 (a) The coordination environment around $\mathrm{Zn}(\mathrm{II})$ ions in 2. (b) $\mathrm{H}$-bonding interactions in 2. [H7C* is at $-1 / 2+x, 3 / 2-y, 1 / 2+z ; H 66 \#$ is at $3 / 2-x,-1 / 2+y, 1 / 2-z]$. (c) Single unit of a rectangular sheet in 2 . (d) $2 D$ rectangular sheet in 2 .

$\left[\mathrm{Zn}_{2}(\mathrm{DDI})_{2} \mathrm{I}\right] \cdot 2 \mathrm{H}_{2} \mathrm{O}$ (4). Single crystal X-ray analysis shows that 4 crystallizes in the triclinic space group $P \overline{1}$ (Table 1), and forms an anionic zwitterion zinc dimer consisting of two Zn(II) ions, two $\mathrm{DDI}^{-}$units, four iodide ions (one-fourth occupancy) and two lattice water molecules. Both $\mathrm{Zn}$ (II) ions lie in a distorted tetrahedral environment (bond angles vary from $101.94^{\circ}$ to $122.35^{\circ}$ ), connected by two individual $\mathrm{DDI}^{-}$ units. Each DDI $^{-}$unit provides two donor oxygen atoms to form a 14-membered macrocyclic ring, while the remaining four sites are occupied by the four iodide ions (Fig. 4a). Unlike 3, in complex 4, the iodide ions are coordinated to the zinc ion terminally and form a dimer, hence thwarting the formation of an extended CP. The oxygen atoms of the $\mathrm{DDI}^{-}$unit are coordinated to zinc in a monodentate terminal fashion (II; Scheme 3), with bond distances of 1.992(4) $\AA$ and 1.966(4) $\AA$ for $\mathrm{Zn}-\mathrm{O} 1$ and $\mathrm{Zn}-\mathrm{O} 4 *$ respectively, ${ }^{9 h}$ whereas the bond distances of $\mathrm{Zn}-\mathrm{I}$ are 2.273(14) $\AA$ and 2.256(13) ^ for Zn-I1 and Zn-I2 respectively. ${ }^{24}$ Within the macrocycle, the orientations of the two $\mathrm{DDI}^{-}$units are anti- parallel to each other, while the iodide ions are perpendicular to the macrocycle. The orientation of the $\mathrm{DDI}^{-}$units and iodide ions facilitates the H-bonding interactions

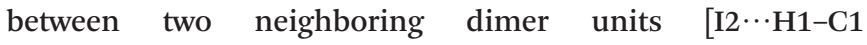
(imidazolium) and I2 $\cdots \mathrm{H} 6 \mathrm{C}$ ( $N$-methyl) (Fig. S9; Table 3 )]. These supramolecular interactions between adjacent dimer units lead to an infinite ladder-shaped 1D supramolecular network (Fig. 4b). The $\mathrm{Zn}$ (II) ions form the connections of the ladder and the distance between $\mathrm{Zn} \cdots \mathrm{Zn}$ in a ladder is 4.840(1) $\AA$ along the rung and 8.489(2) $\AA$ along the rail (Fig. S10).

$\left[\mathrm{Zn}(\mathrm{DDI})_{2}\left(\mathrm{H}_{2} \mathrm{O}\right)_{3}\right] \cdot 2 \mathrm{H}_{2} \mathrm{O}$ (5). It was observed that using aq. $\mathrm{NH}_{3}$ doesn't always facilitate the complete removal of $\mathrm{HX}$ $\left(\mathrm{Cl}^{-}\right.$or $\left.\mathrm{I}^{-}\right)$and hence the expected CPs probably were not observed. Keeping this in mind $\mathrm{Et}_{3} \mathrm{~N}$ which is a stronger base as compared to aqueous $\mathrm{NH}_{3}$ was used in the reaction medium. Thus, complex 5 was obtained by using a stoichiometric ratio of $1: 1$ of the ligand and $\mathrm{Zn}\left(\mathrm{NO}_{3}\right)_{2} \cdot 6 \mathrm{H}_{2} \mathrm{O}$, using $\mathrm{Et}_{3} \mathrm{~N}$ as base in a $\mathrm{CH}_{3} \mathrm{CN}-\mathrm{H}_{2} \mathrm{O}$ mixture at room temperature. 
Table 2 Selected bond distances (Å) and angles (deg) for compounds 2-6

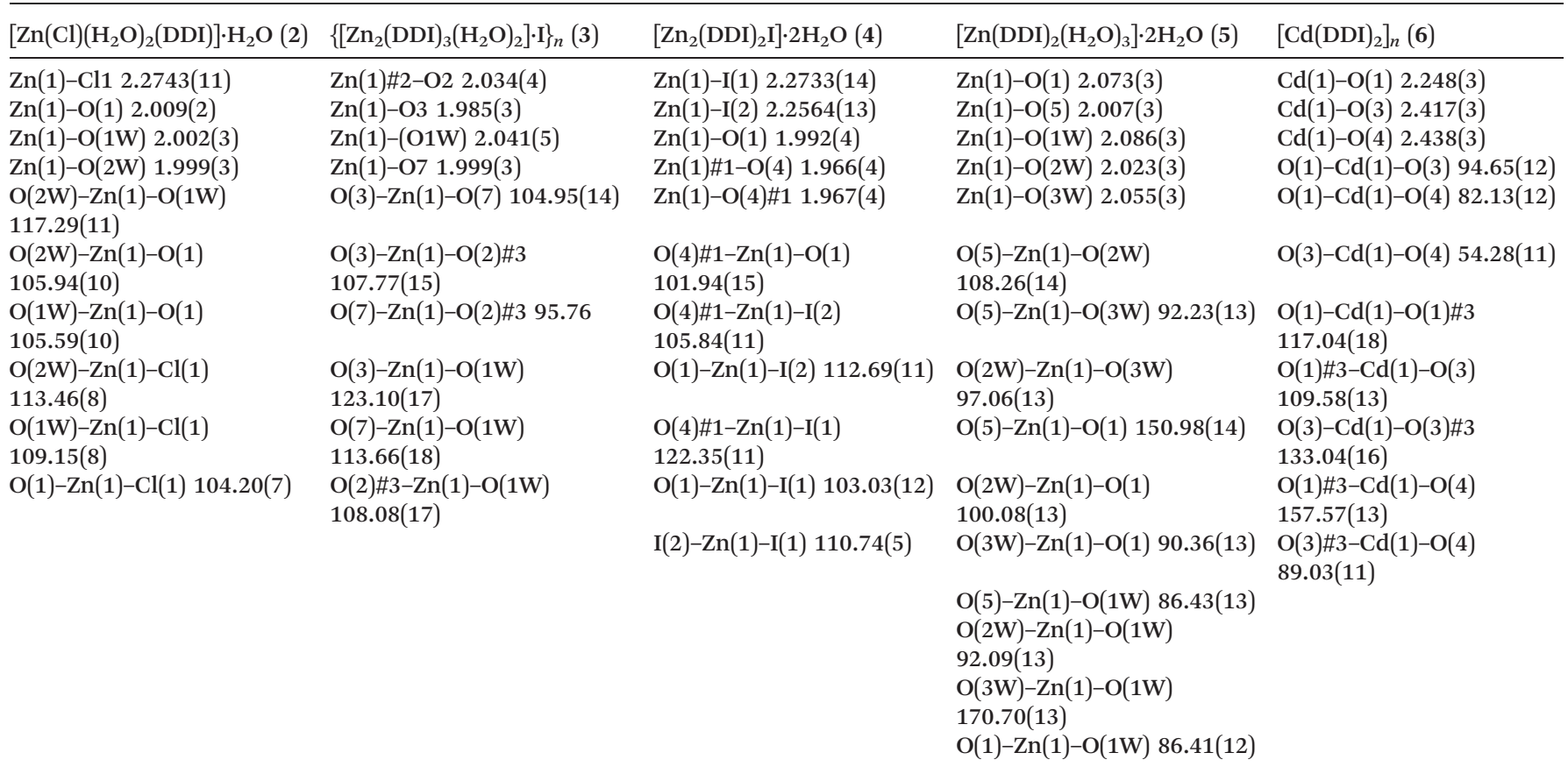

${ }^{a}$ Symmetry codes for $3 \# 1-x+1 / 2,-y+1 / 2, z \# 2-x, y+1 / 2,-z+1 / 2 \# 3-x, y-1 / 2,-z+1 / 2 ; 4 \# 1-x+1,-y+2,-z+1 ; 6 \# 1 x-1 / 2, y-1 / 2, z$ $\# 2 x+1 / 2, y+1 / 2, z \# 3-x+2, y,-z+1 / 2$.

Table 3 Hydrogen bonding interaction parameters in 1-6

\begin{tabular}{|c|c|c|c|}
\hline$(\mathrm{D}-\mathrm{H} \cdots \mathrm{A})$ & $d(\mathrm{H} \cdots \mathrm{A})(\AA)$ & $d(\mathrm{D} \cdots \mathrm{A})(\AA)$ & $<(\mathrm{A} \cdots \mathrm{H}-\mathrm{D})\left(^{\circ}\right.$ \\
\hline \multicolumn{4}{|l|}{1} \\
\hline $\mathrm{C} 1-\mathrm{H} 1 * \cdots \mathrm{O} 1$ & 2.22 & $3.13(4)$ & 161 \\
\hline $\mathrm{C} 1-\mathrm{H} 1 * \cdots \mathrm{O} 2$ & 2.69 & $3.52(1)$ & 146 \\
\hline C6-H6C\# $\cdots \mathrm{O} 4$ & 2.57 & $3.33(2)$ & 134 \\
\hline $\mathrm{O} 3-\mathrm{H} 3 \cdots \mathrm{O} 2$ & 1.58 & $2.42(6)$ & 177 \\
\hline $\mathrm{C} 5=\mathrm{O} 4 \cdots \mathrm{C} 1 \mathrm{~S}$ & $2.89(5)$ & & 133 \\
\hline \multicolumn{4}{|l|}{2} \\
\hline O2W-H66\# $\cdots \mathrm{Cl} 1$ & 2.66 & $3.46(5)$ & 151 \\
\hline $\mathrm{C} 7-\mathrm{H} 7 \mathrm{C}^{* \cdots} \mathrm{Cl} 1$ & 2.69 & $3.61(9)$ & 163 \\
\hline $\mathrm{O} 3 \mathrm{~W}-\mathrm{H} 78 \cdots \mathrm{O} 4$ & 2.10 & $2.92(1)$ & 171 \\
\hline $\mathrm{C} 1-\mathrm{H} 1 \cdots \mathrm{O} 3 \mathrm{~W}$ & 2.28 & $3.12(7)$ & 150 \\
\hline \multicolumn{4}{|l|}{3} \\
\hline O5-H15 $\cdots$ I1\# & 3.01 & $3.84(1)$ & 162 \\
\hline C9-H9B $\cdots$ I1\# & 3.12 & $4.00(4)$ & 153 \\
\hline \multicolumn{4}{|l|}{4} \\
\hline $\mathrm{C} 1-\mathrm{H} 1 \cdots \mathrm{I} 2$ & 2.55 & $3.40(3)$ & 150 \\
\hline C6-H6C $\cdots \mathrm{I} 2$ & 2.79 & $3.68(9)$ & 152 \\
\hline \multicolumn{4}{|l|}{5} \\
\hline 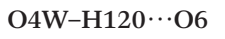 & 1.88 & $2.67(7)$ & 166 \\
\hline O5W-H131 $\cdots$ O7 & 2.06 & $2.88(1)$ & 176 \\
\hline $\mathrm{C} 14-\mathrm{H} 14 \mathrm{~A} \cdots \mathrm{O} 7$ & 2.69 & $3.56(2)$ & 151 \\
\hline $\mathrm{O} 1 \mathrm{~W}-\mathrm{H} 9 \cdots \mathrm{O} 7$ & 1.98 & $2.75(1)$ & 158 \\
\hline $\mathrm{O} 2 \mathrm{~W}-\mathrm{H} 100 \cdots \mathrm{O} 8$ & 1.96 & $2.70(9)$ & 152 \\
\hline \multicolumn{4}{|l|}{6} \\
\hline $\mathrm{C} 1-\mathrm{H} 4 \cdots \mathrm{O} 2$ & 2.20 & $2.97(4)$ & 140 \\
\hline $\mathrm{C} 7-\mathrm{H} 5 \mathrm{C} \cdots \mathrm{O} 3$ & 2.41 & $3.28(9)$ & 152 \\
\hline
\end{tabular}

1. $\mathrm{H} 1 *$ is at $-1 / 2+x, 1 / 2-y,-1 / 2+z$; $\mathrm{H} 6 \mathrm{C} \#$ is at $x, 1+y, z$; 1 \$ is at $1 / 2-x, 1 / 2+y, 1 / 2+z$. 2. H7C* is at $-1 / 2+x, 3 / 2-y, 1 / 2+z$; H66\# is at $3 / 2-x,-1 / 2+y, 1 / 2-z]$. 3 . I1 \# is at $1 / 2-x,-1+y,-1 / 2+z$.
The same reaction procedure using $\mathrm{ZnCl}_{2}$ was not successful. Single crystal X-ray diffraction shows that 5 crystallizes in the monoclinic space group $P 2_{1} / c$ (Table 1 ), and consists of one $\mathrm{Zn}$ (II) ion, two DDI ${ }^{-}$units, three coordinated $\mathrm{H}_{2} \mathrm{O}$ molecules and two lattice $\mathrm{H}_{2} \mathrm{O}$ molecules. $\mathrm{Zn}$ (II) lies in an octahedral environment and three of the coordination sites are occupied by three O-atoms from the two $\mathrm{DDI}^{-}$units. Interestingly, in this case two coordination modes of $\mathrm{DDI}^{-}$ were observed viz. monodentate terminal and bidentate chelate. One of the $\mathrm{DDI}^{-}$units coordinates to $\mathrm{Zn}$ (II) in a monodentate terminal fashion, while the second unit of $\mathrm{DDI}^{-}$ shows bidentate chelate mode (III; Scheme 3). The remaining three sites are occupied by three $\mathrm{H}_{2} \mathrm{O}$ molecules (Fig. 5a). Like 1 and 2, a loss of $\mathrm{HI}$ is observed in $\mathbf{5}$, however the final product obtained here is once again an anionic zwitterion zinc complex formed by $\mathrm{DDI}^{-}$.

The $\mathrm{Zn}-\mathrm{O}$ bond length in $\mathbf{5}$ is found to be in the range of $2.007(3) \AA$ to 2.086 (3) $\AA$ which is comparable to literature values. ${ }^{9 h}$ The bond angles in 5 vary from $86.41(12)^{\circ}$ to $170.70(13)^{\circ}$ (Table 2). Two of the monomer units are connected to each other by H-bonding and form an 18membered macrocycle (Fig. 5b). Each of these macrocycles consists of two $\mathrm{DDI}^{-}$units coordinated in monodentate terminal mode from two adjacent monomers, while the remaining two $\mathrm{DDI}^{-}$units coordinated in bidentate chelate mode lack any such supramolecular interactions. These monomer units along with the coordinated and lattice $\mathrm{H}_{2} \mathrm{O}$ molecules further extend the macrocycle through $\mathrm{CH} \cdots \mathrm{O}$ 


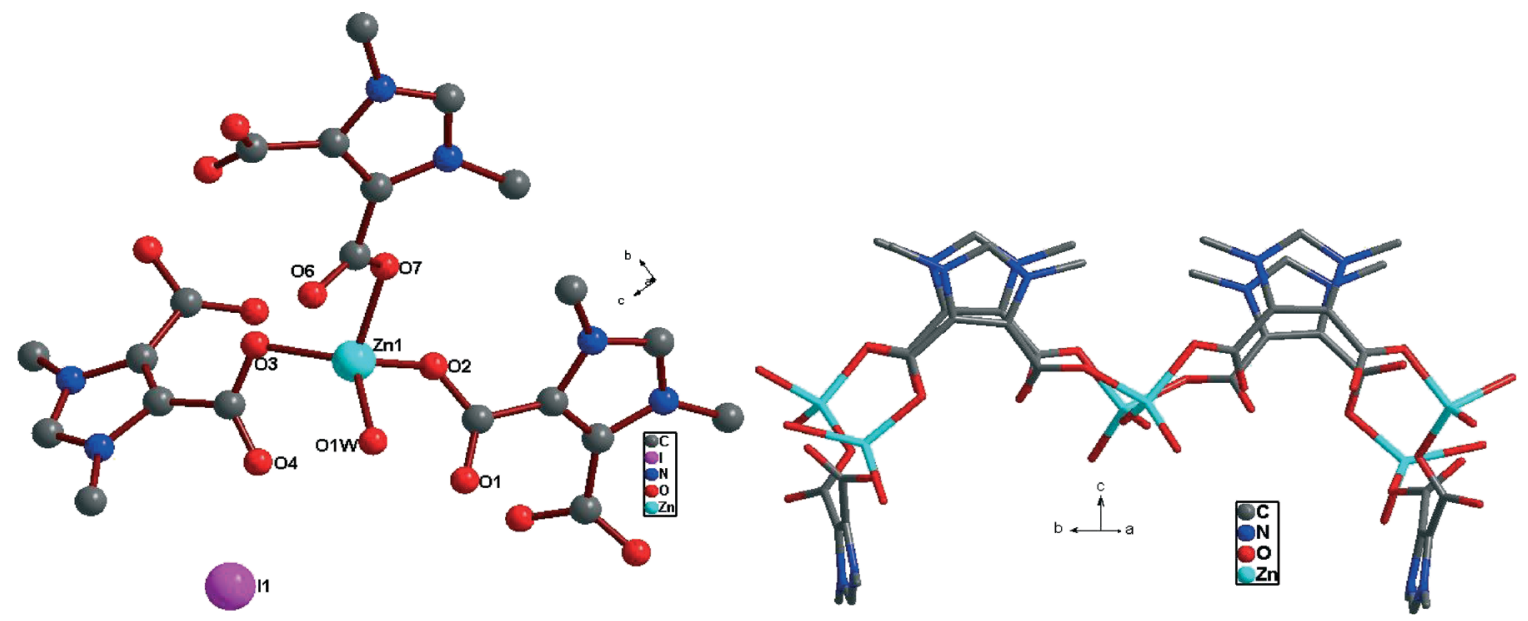

(a)

(b)

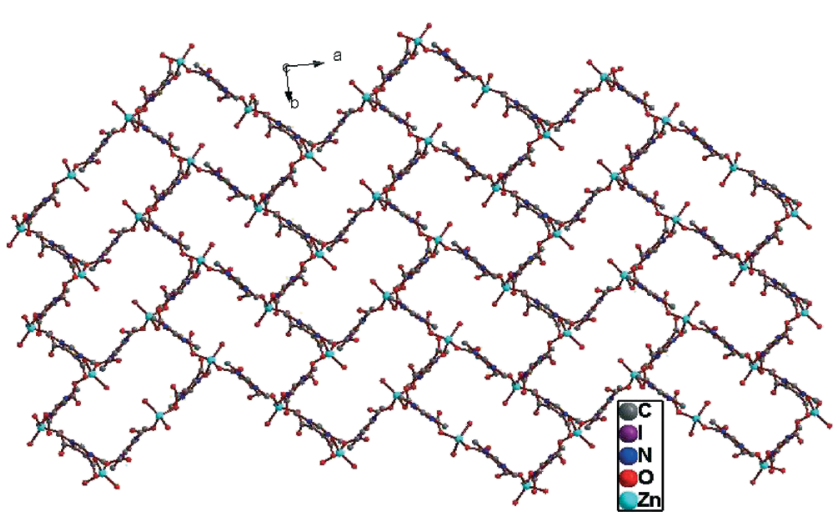

(c)

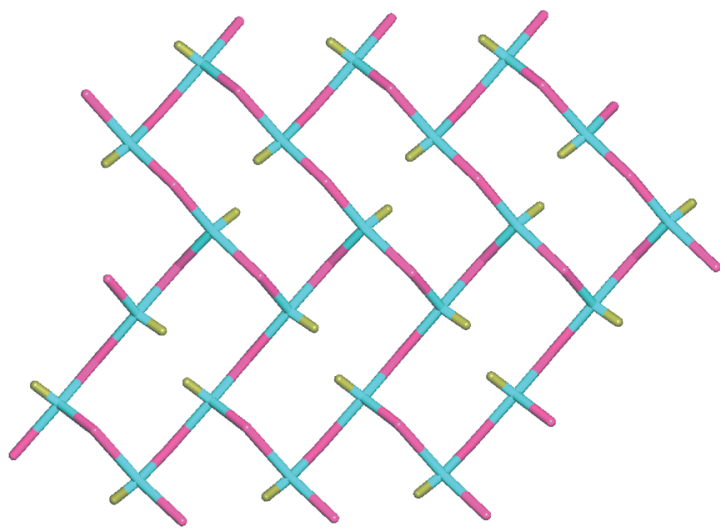

(d)

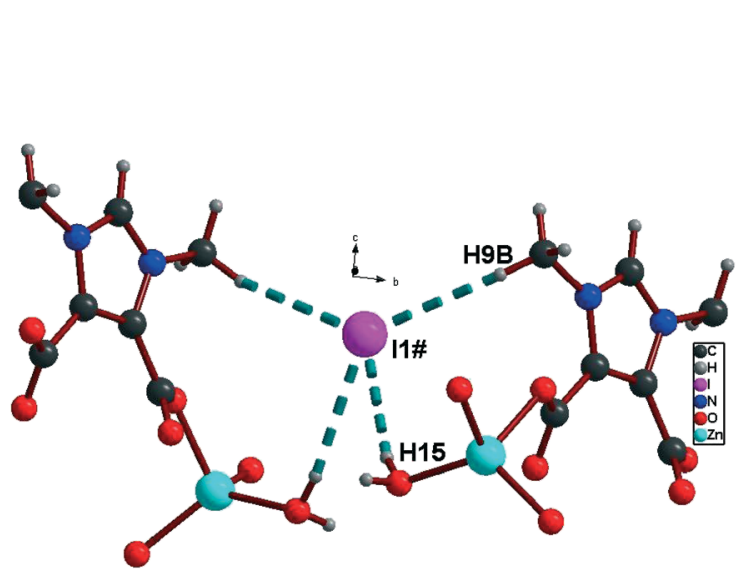

(e)

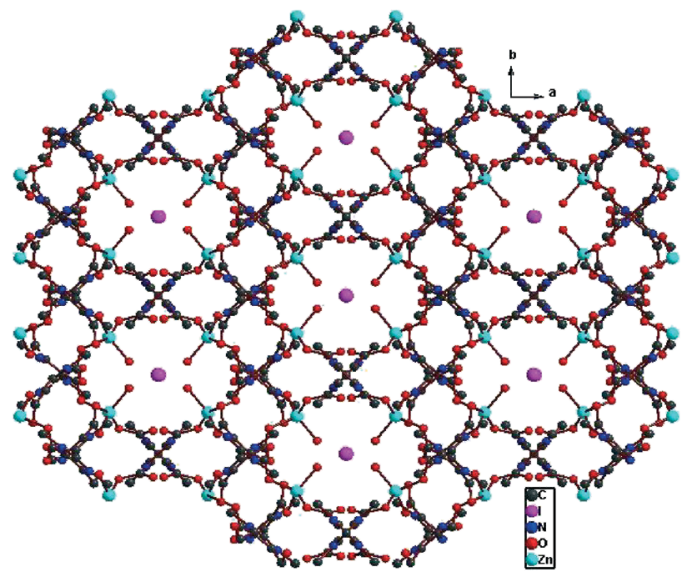

(f)

Fig. 3 (a) The coordination environment around $\mathrm{Zn}($ II) ions in 3 (hydrogen atoms are omitted for clarity). (b) Hexameric 42-membered crownshaped macrocycle ring in 3. (c) 2D herringbone pattern in 3. (d) Topological representation of 3-connected nodes in 3 . (e) $\mathrm{H}$-bonding interactions in 3 [I1\# is at $1 / 2-x,-1+y,-1 / 2+z]$. (f) $3 D$ supramolecular network of 3 with iodide ions. 


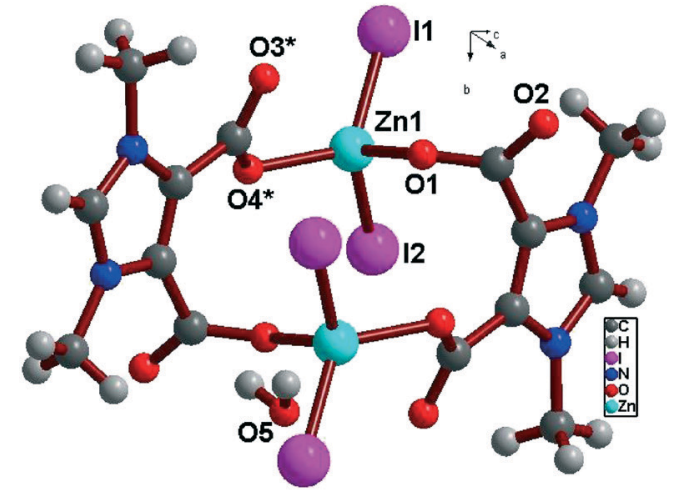

(a)

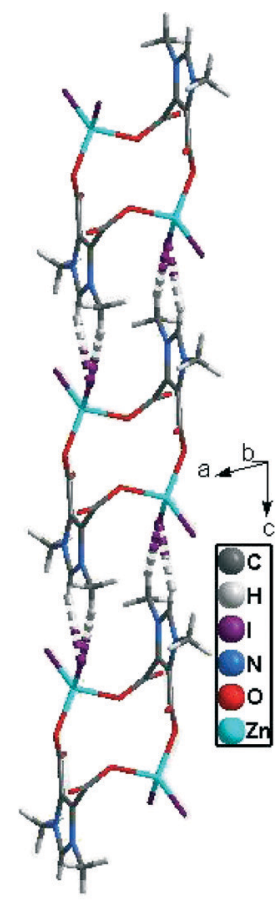

(b)

Fig. 4 (a) The coordination environment around $\mathrm{Zn}(\mathrm{II})$ ions in 4 . [O3* and O4* are at equivalent positions $1-x, 2-y, 1-z$ ]. (b) Infinite laddershaped 1D supramolecular network of 4 .

interactions and $\mathrm{H}$-bonds (Table 3, Fig. 5c) and result in a 2D supramolecular network.

$\left[\mathrm{Cd}(\mathrm{DDI})_{2}\right]_{n}(6)$. In order to evaluate the metal ion effect, the reaction was carried out using cadmium nitrate and $\mathrm{NEt}_{3}$ under similar conditions to those of 5 . The same synthetic procedure as that for $\mathbf{2 - 4}$ was not fruitful in this case and performing the same reaction by using $\mathrm{CdCl}_{2}$ was not successful. Single crystal X-ray diffraction shows that 6 crystallizes in the monoclinic space group $C 2 / c$ (Table 1). In 6, each $\mathrm{Cd}(\mathrm{II})$ ion lies in a twofold axis and is in a distorted octahedron environment coordinated by six donor O-atoms provided by four anionic DDI ${ }^{-}$units (Fig. 6a). Similar to 5, in 6 two coordination modes of $\mathrm{DDI}^{-}$, i.e. monodentate terminal and bidentate chelate, were observed. Two of the $\mathrm{DDI}^{-}$units are coordinated to the $\mathrm{Cd}$ (II) ion in bidentate chelate mode, while the remaining two $\mathrm{DDI}^{-}$units are coordinated in monodentate terminal mode (III; Scheme 3). The Cd-O bond distance in 6 falls in the range of 2.417(3) $\AA$ to 2.248(3) $\AA$, all of which are comparable to those reported for other imidazolebased dicarboxylate Cd(II) complexes (Table 2). ${ }^{9 h, i}{\text { The } \text { DDI }^{-}}^{-}$ units, which are coordinated to one $\mathrm{Cd}$ (II) ion in bidentate chelate mode, are further coordinated to another $\mathrm{Cd}(\mathrm{II})$ ion in monodentate terminal mode and vice versa. Thus, there exists a tetrameric 28-membered macrocyclic ring (Fig. 6b). Each macrocycle consists of four $\mathrm{Cd}(\mathrm{II})$ ions which are coordinated to four $\mathrm{DDI}^{-}$units and the distance between two $\mathrm{Cd}(\mathrm{II})$ centers was found to be 8.025(6) $\AA$. The four $\mathrm{DDI}^{-}$units are oriented perpendicular to each other. Further, each of these tetramer units in $\mathbf{6}$ extends through the remaining carboxylate oxygen atoms forming another tetramer and results in a 2D anionic zwitterion cadmium CP showing an interesting "fish scale pattern" (Fig. 6c). Through topological analysis, 6 can be represented as a $4^{4} 6^{2}$ sql topology with the Cd centre as a 4-connected uninodal net (Fig. 6d). The 2D CP is further connected through the intermolecular $\mathrm{CH} \cdots \mathrm{O}$ interactions existing between carboxylate oxygen with different H-donor carbon atoms, to form a 3D supramolecular network (Fig. 6e). The 3D supramolecular network shows packing in an ABAB fashion with the adjacent layer (Table 3, Fig. S11 and S12).

\section{Thermogravimetric and powder X-ray diffraction analyses}

The thermal stability of 2-6 was studied using thermogravimetric analysis (TGA) (Fig. 7). The TGA curve of 2 shows an initial weight loss of $26.2 \%$ (calculated $26.46 \%$ ) up to $211^{\circ} \mathrm{C}$, corresponding to the loss of one chloride ion, two coordinated water molecules and one lattice water molecule. At $255{ }^{\circ} \mathrm{C}, 2$ shows a gradual decrease in weight due to continuous loss of the ligand (residue $28.4 \%$ ). The TGA curve of 3 shows an initial weight loss of $3.3 \%$ (calculated $2.13 \%$ ) at $96.68{ }^{\circ} \mathrm{C}$ corresponding to the loss of one coordinated water molecule. The second weight loss of $27 \%$ (calculated $22 \%$ ) at $149{ }^{\circ} \mathrm{C}$ corresponds to loss of one of the coordinated ligands. The third weight loss of $42 \%$ (calculated $43.9 \%$ ) at $262{ }^{\circ} \mathrm{C}$ shows the loss of the remaining two coordinated ligands (residue 27.7\%). The TGA curve of 4 shows that it is stable up to $180{ }^{\circ} \mathrm{C}$ and shows an initial weight loss of $32.7 \%$ (calculated $33.49 \%$ ) at $185{ }^{\circ} \mathrm{C}$, corresponding to the loss of one ligand and two 


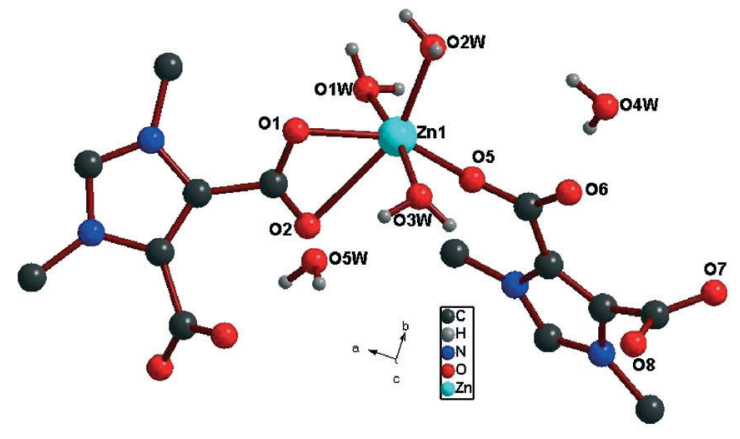

(a)

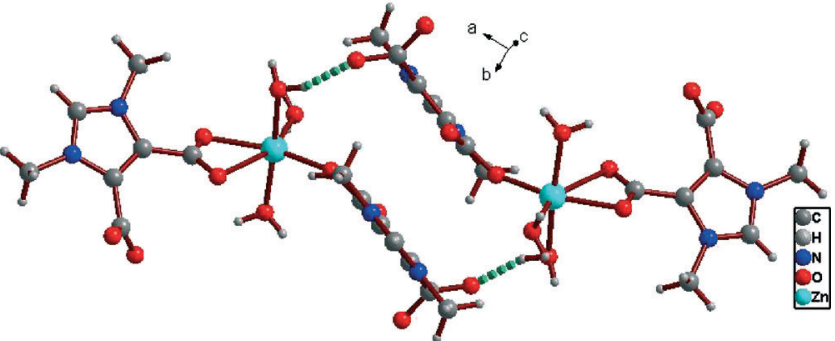

(b)

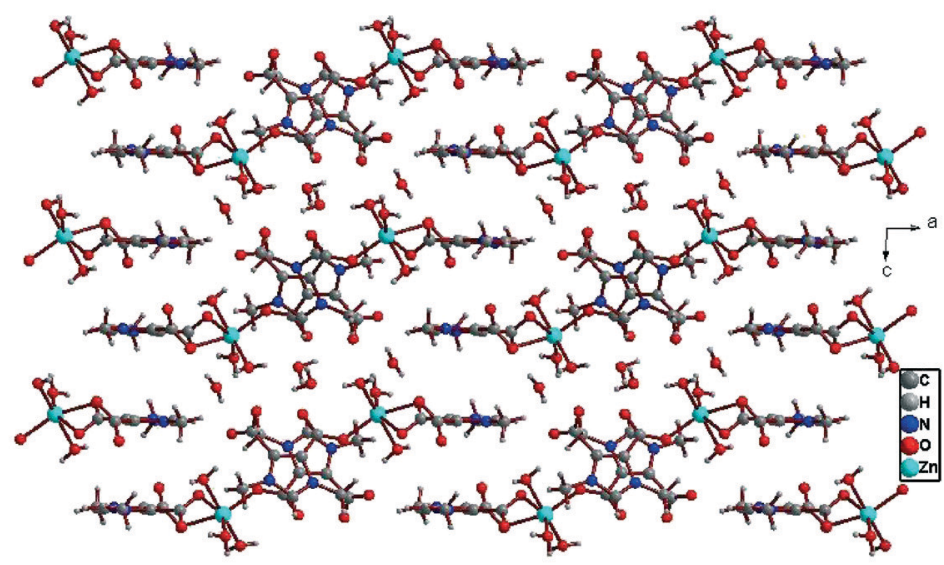

(c)

Fig. 5 (a) The coordination environment around $\mathrm{Zn}(\mathrm{II})$ ions in 5. (b) 18-membered macrocycle of 5. (c) 2D supramolecular network of 5 (H-bonds are omitted for clarity).

lattice water molecules. At $250{ }^{\circ} \mathrm{C}, 4$ shows a gradual weight loss due to the loss of one ligand unit and iodide ions (residue $20.7 \%$ ). The TGA curve of 5 shows that it is stable up to $193{ }^{\circ} \mathrm{C}$ and shows a sudden weight loss of $90 \%$ at $250{ }^{\circ} \mathrm{C}$, corresponding to the loss of the coordinated ligands and water molecules (residue 10\%). The TGA curve of 6 shows that it is stable up to $200{ }^{\circ} \mathrm{C}$ and shows a gradual weight loss of $62.91 \%$ (calculated $64.68 \%$ ) corresponding to the loss of four ligand units which are coordinated to $\mathrm{Cd}$ (II) (residue $37.09 \%$ ).

To confirm the sample purity, powder X-ray diffraction was performed on compounds 1-6 and it was observed that the simulated spectra correlate with the experimental spectra, which confirms the phase purity of these compounds at room temperature (Fig. S13). To confirm the stability of complexes 2-6 at high temperature, variable temperature PXRD was also performed and it was observed that all the complexes are stable up to $100{ }^{\circ} \mathrm{C}$. Complex 3 was found to be stable even after heating at $160{ }^{\circ} \mathrm{C}$, while complexes 4-6 were found to be stable even at $200{ }^{\circ} \mathrm{C}$. To check the reversibility of water removal in CP 3, it was first heated at $100{ }^{\circ} \mathrm{C}$ and then re-immersed in water; it was found that the PXRD pattern of the re-immersed compound does not match with that of CP 3 confirming the irreversible nature of water removal (Fig. S14).

\section{Photoluminescence}

CPs consisting of transition metals with a $\mathrm{d}^{10}$ electronic configuration such as $\mathrm{Zn}$ and $\mathrm{Cd}$ and suitable organic chromophores are found to exhibit excellent photoluminescence properties. ${ }^{25}$ Therefore the complexes synthesized by using these metal ions can be employed as new luminescent materials. Consequently, the photoluminescence properties of complexes 2-6 were investigated at room temperature (Fig. 8). In the solid state, unlike imidazole-4,5-dicarboxylic acid $\left(\mathrm{H}_{3} \mathrm{IDC}\right)$ and its different analogue ligands which show moderate to weak luminescence, the free $\mathrm{H}_{2}$ DDII shows intense luminescence with emission maximum at $348 \mathrm{~nm}$ $\left(\lambda_{\mathrm{ex}} 315 \mathrm{~nm}\right)$ due to the $\pi^{*}-\pi$ transition as well as XLCT (halide to ligand charge transfer) due to iodide ions. ${ }^{8} \mathrm{Com}-$ pounds 2-4 are red shifted from the ligand and exhibit intense luminescence emission at $397 \mathrm{~nm}\left(\lambda_{\mathrm{ex}} 250 \mathrm{~nm}\right), 396$ $\mathrm{nm}\left(\lambda_{\mathrm{ex}} 250 \mathrm{~nm}\right)$ and $395 \mathrm{~nm}\left(\lambda_{\mathrm{ex}} 265 \mathrm{~nm}\right)$, respectively. A similar red shift in the luminescence emission as well as fluorescence quenching, due to a decrease in intensity, was observed in compounds 5 and 6 at $398 \mathrm{~nm}\left(\lambda_{\text {ex }} 255 \mathrm{~nm}\right)$ and $422 \mathrm{~nm}\left(\lambda_{\mathrm{ex}} 365 \mathrm{~nm}\right)$, respectively, as compared to the ligand. The cause of red shift for compounds $2-6$ can be attributed 


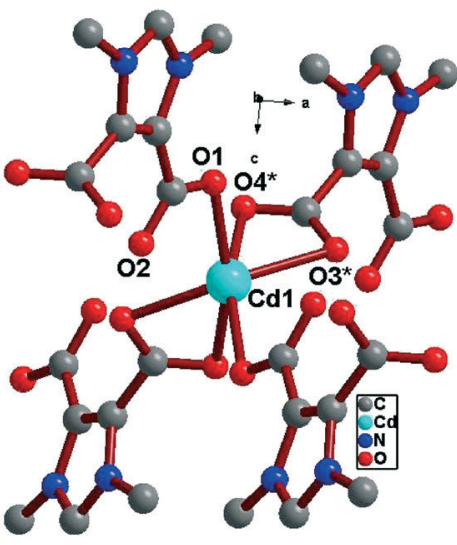

(a)

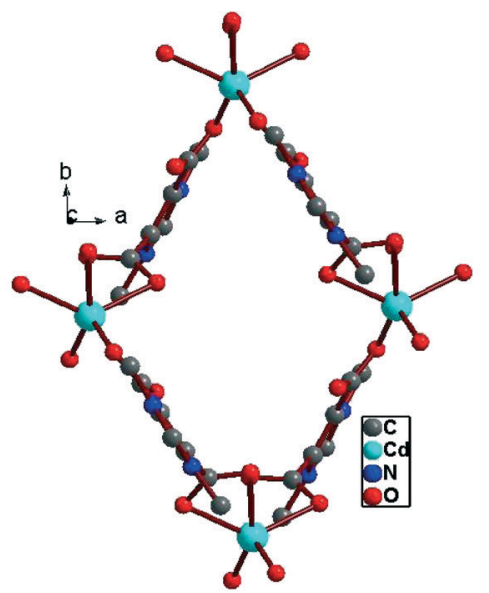

(b)

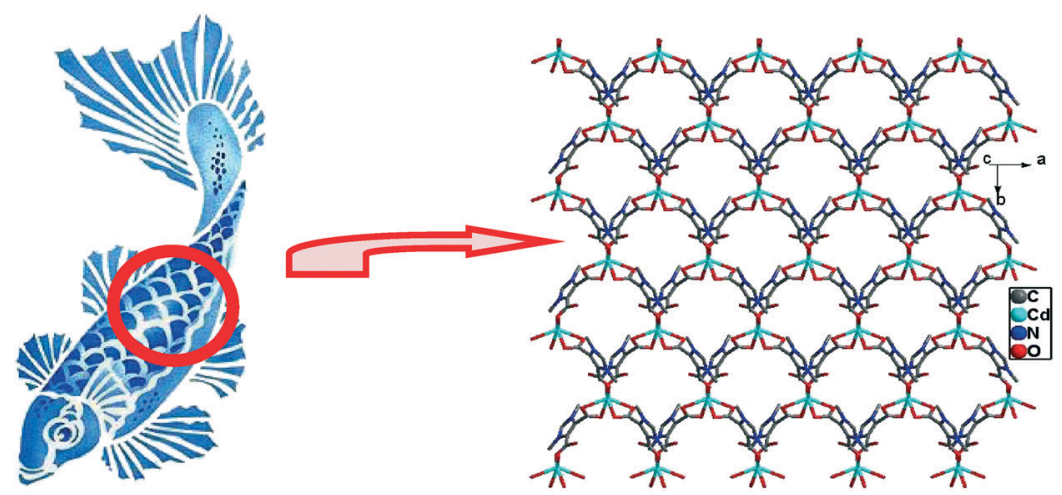

(c)

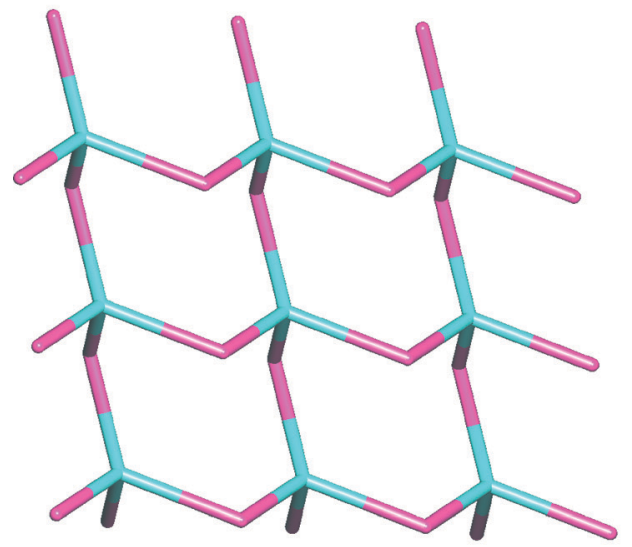

(d)

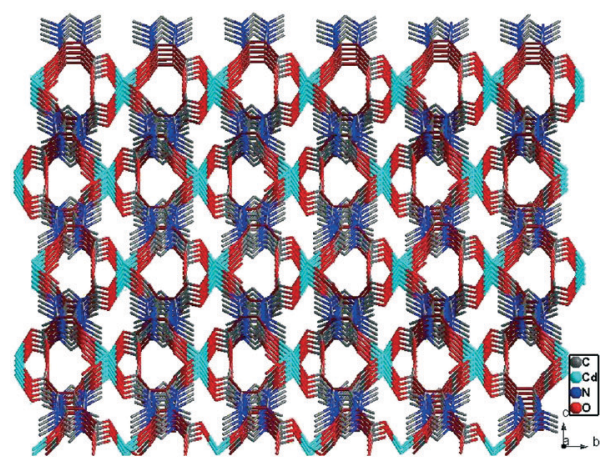

(e)

Fig. 6 (a) The coordination environment around Cd(I) ions in 6 (hydrogen atoms are omitted for clarity). [O3* and O4* are at equivalent positions 3/2 - $x$, $1 / 2+y, 1 / 2-z]$. (b) Tetrameric 28-membered macrocyclic ring of 6. (c) Fish scale pattern of 2D CP 6. (d) Topological representation of 4-connected nodes in 6. (e) 3D supramolecular structure of 6 .

to ligand to metal charge transfer (LMCT) transition. ${ }^{8 c, 25 c}$ The difference in the emissive properties of complexes 2-4 as compared to 5-6 having the same ligand could be due to the presence of anions, $\mathrm{Cl}^{-}(2)$ and $\mathrm{I}^{-}(3$ and 4$)$, and the difference in the coordination environment around the metal ion and variable architectures. ${ }^{25 c, 26}$ The anion plays an important role in the fluorescence properties of these complexes by enhancing the intensity by XLCT transition, which consequently reduces the probability of fluorescence quenching. On the removal of the anion in $\mathbf{5}$, in spite of having the same metal 


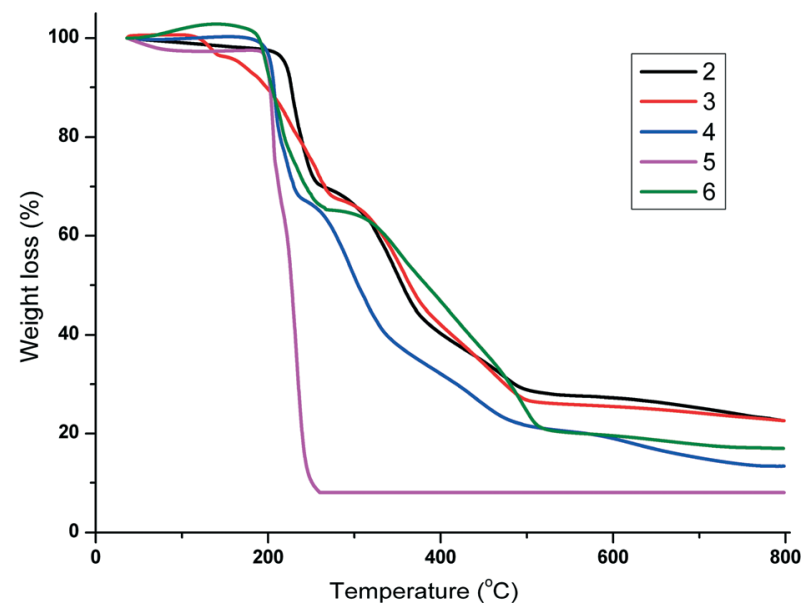

Fig. 7 TGA curves of compounds 2-6.

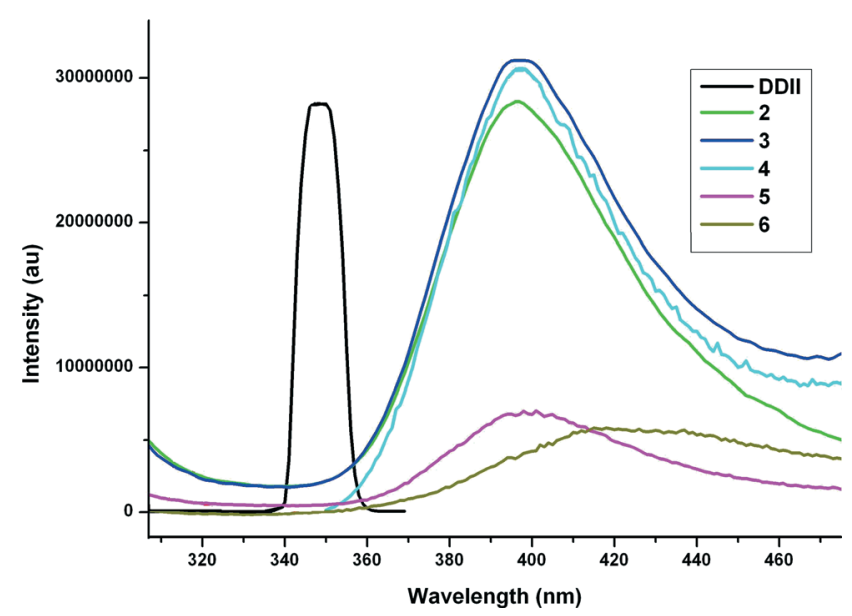

Fig. 8 Solid state photoluminescence spectra of compounds 2-6.

ion, $\mathrm{Zn}(\mathrm{II})$, and ligand as those of $\mathbf{2 - 4}$, a large decrease in the fluorescence intensity was observed due to the absence of XLCT transition. The quenching in 6 can be explained by the absence of XLCT and by taking into consideration the presence of the heavy atom perturbation effect due to $\mathrm{Cd}$ which decreases the luminescence intensity due to nonradiative energy dissipation. ${ }^{27}$

\section{Conclusions}

In summary, we have designed a rigid imidazolium dicarboxylate ligand, $\mathrm{H}_{2} \mathrm{DDII}$, which upon crystallization forms the zwitterionic structure HDDI (1). Five anionic zwitterion metal complexes and/or CPs were synthesized, namely, $\left[\mathrm{Zn}(\mathrm{Cl})\left(\mathrm{H}_{2} \mathrm{O}\right)_{2}(\mathrm{DDI})\right] \cdot \mathrm{H}_{2} \mathrm{O}(2),\left\{\left[\mathrm{Zn}_{2}(\mathrm{DDI})_{3}\left(\mathrm{H}_{2} \mathrm{O}\right)_{2}\right] \cdot \mathrm{I}\right\}_{n}$ (3), $\left[\mathrm{Zn}_{2}(\mathrm{DDI})_{2} \mathrm{I}\right] \cdot 2 \mathrm{H}_{2} \mathrm{O}(4),\left[\mathrm{Zn}(\mathrm{DDI})_{2}\left(\mathrm{H}_{2} \mathrm{O}\right)_{3}\right] \cdot 2 \mathrm{H}_{2} \mathrm{O}(5)$ and $[\mathrm{Cd}-$ $\left.(\mathrm{DDI})_{2}\right]_{n}(6)$, exhibiting different architectures ranging from discrete molecular units to 2D CPs. Complexes 2 and 5 were monomeric units, while 4 was a dimer which formed an infinite 1D ladder through supramolecular interactions. CP 3 and CP 6 resulted in 2D CPs with herringbone and fish scale patterns, respectively. The stoichiometric ratio of metal to ligand, nature of metal salt, solvent conditions and nature of base influenced the structure of the resulting complexes. The iodide ion is present either as a coordinating anion to the metal centre or captured inside the $\mathrm{CP}$ as a counter anion. Further, the solid state photoluminescence properties of $\mathrm{H}_{2}$ DDII and compounds 2-6 were also investigated. Compared to the imidazole or substituted imidazole dicarboxylic acids strong emission was exhibited by $\mathrm{H}_{2}$ DDII and compounds 2-6. Employing these complexes/CPs as support systems is in progress.

\section{Acknowledgements}

The authors thank the Council of Scientific and Industrial Research (CSIR), the Department of Science and Technology (DST), the Government of India for financial support and the Indian Institute of Technology (IIT), Kanpur, for infrastructural facilities. We also thank "Thematic Unit of Excellence on Soft Nanofabrication with Application in Energy, Environment and Bioplatform at IIT Kanpur" and PG Research lab, Department of Chemical Engineering, IIT Kanpur, for the PXRD facility. ST thanks CSIR for the research fellowship. We are thankful to Mr. Musheer Ahmad for helping us by drawing the nets using TOPOS.

\section{References}

1 (a) Y.-B. Zhang and J.-P. Zhang, Pure Appl. Chem., 2013, 85, 405; (b) R. L. LaDuca, Coord. Chem. Rev., 2009, 253, 1759; (c) D. J. Tranchemontagne, J. L. Mendoza-Cortés, M. O'Keeffe and O. M. Yaghi, Chem. Soc. Rev., 2009, 38, 1257; (d) S. I. Vagin, A. K. Ott and B. Rieger, Chem. Ing. Tech., 2007, 79, 767; (e) N. Guillou, C. Livage and G. Férey, Eur. J. Inorg. Chem., 2006, 4963; $(f)$ W. Mori, S. Takamizawa, C. N. Kato, T. Ohmura and T. Sato, Microporous Mesoporous Mater., 2004, 73, 31; (g) A. Erxleben, Coord. Chem. Rev., 2003, 246, 203; (h) O. M. Yaghi, M. O'Keeffe, N. W. Ockwig, H. K. Chae, M. Eddaoudi and J. Kim, Nature, 2003, 423, 705; (i) M. Eddaoudi, D. B. Moler, H. Li, B. Chen, T. M. Reineke, M. O'Keeffe and O. M. Yaghi, Acc. Chem. Res., 2001, 34, 319.

2 (a) H. Furukawa, K. E. Cordova, M. O'Keeffe and O. M. Yaghi, Science, 2013, 341, 974; (b) Z.-J. Lin, L.-W. Han, D.-S. Wu, Y.-B. Huang and R. Cao, Cryst. Growth Des., 2013, 13, 255; (c) J. Sahu, M. Ahmad and P. K. Bharadwaj, Cryst. Growth Des., 2013, 13, 2618; (d) Y.-S. Xue, F.-Y. Jin, L. Zhou, M.-P. Liu, Y. Xu, H.-B. Du, M. Fang and X.-Z. You, Cryst. Growth Des., 2012, 12, 6158; (e) Y.-L. Gai, K.-C. Xiong, L. Chen, Y. Bu, X.-J. Li, F.-L. Jiang and M.-C. Hong, Inorg. Chem., 2012, 51, 13; $(f)$ K. S. Jeong, Y. B. Go, S. M. Shin, S. J. Lee, J. Kim, O. M. Yaghi and N. Jeong, Chem. Sci., 2011, 2, 877; $(g)$ M. Du, C.-P. Li, J.-M. Wu, J.-H. Guo and G.-C. Wang, Chem. Commun., 2011, 47, 8088.

3 (a) J.-Y. Wua, C.-W. Yang, H.-F. Chen, Y.-C. Jao, S.-M. Huang, C. Tsai, T.-W. Tseng, G.-H. Lee, S.-M. Peng and K.-L. Lu, J. Solid State Chem., 2011, 184, 1740; (b) M. A. Nadeem, M. Bhadbhade, R. Bircher and J. A. Stride, Cryst. Growth 
Des., 2010, 10, 4060; (c) G.-Q. Kong and C.-D. Wu, Cryst. Growth Des., 2010, 10, 4590; (d) J. K. Schnobrich, O. Lebel, K. A. Cychosz, A. Dailly, A. G. Wong-Foy and A. J. Matzger, J. Am. Chem. Soc., 2010, 132, 13941; (e) J.-S. Hu, Y.-J. Shang, X.-Q. Yao, L. Qin, Y.-Z. Li, Z.-J. Guo, H.-G. Zheng and Z.-L. Xue, Cryst. Growth Des., 2010, 10, 4135; $(f)$ R. P. Davies, R. Less, P. D. Lickiss, K. Robertson and A. J. P. White, Cryst. Growth Des., 2010, 10, 4571; $(g)$ S. Barman, H. Furukawa, O. Blacque, K. Venkatesan, O. M. Yaghi and H. Berke, Chem. Commun., 2010, 46, 7981; (h) H. Furukawa, N. Ko, Y. B. Go, N. Aratani, S. B. Choi, E. Choi, A. Ö. Yazaydin, R. Q. Snurr, M. O'Keeffe, J. Kim and O. M. Yaghi, Science, 2010, 329, 424; (i) M. E. Braun, C. D. Steffek, J. Kim, P. G. Rasmussen and O. M. Yaghi, Chem. Commun., 2001, 2532; (j) D. T. Vodak, M. E. Braun, J. Kim, M. Eddaoudi and O. M. Yaghi, Chem. Commun., 2001, 2534.

4 (a) P. Kanoo, G. Mostafa, R. Matsuda, S. Kitagawa and T. K. Maji, Chem. Commun., 2011, 47, 8106; (b) M.-S. Liu, Q.-Y. Yu, Y.-P. Cai, C.-Y. Su, X.-M. Lin, X.-X. Zhou and J.-W. Cai, Cryst. Growth Des., 2008, 8, 4083; (c) M. Frisch and C. L. Cahill, Cryst. Growth Des., 2008, 8, 2921; (d) C.-D. Wu, P. Ayyappan, O. R. Evans and W. Lin, Cryst. Growth Des., 2007, 7, 1690; (e) S. K. Ghosh, G. Savitha and P. K. Bharadwaj, Inorg. Chem., 2004, 43, 5495.

5 (a) C. S. Hawes and P. E. Kruger, RSC Adv., 2014, 4, 15770; (b) X.-L. Qi, C. Zhang, B.-Y. Wang, W. Xue, C.-T. He, S.-Y. Liu, W.-X. Zhang and X.-M. Chen, CrystEngComm, 2013, 15, 9530; (c) S. Barman, H. Furukawa, O. Blacque, K. Venkatesan, O. M. Yaghi, G.-X. Jinc and H. Berke, Chem. Commun., 2011, 47, 11882; (d) F. Salles, G. Maurin, C. Serre, P. L. Llewellyn, C. Knöfel, H. J. Choi, Y. Filinchuk, L. Oliviero, A. Vimont, J. R. Long and G. Férey, J. Am. Chem. Soc., 2010, 132, 13782; (e) M. Casarin, C. Corvaja, C. D. Nicola, D. Falcomer, L. Franco, M. Monari, L. Pandolfo, C. Pettinari and F. Piccinelli, Inorg. Chem., 2005, 44, 6265.

6 (a) Z. Xia, Q. Wei, Q. Yang, C. Qiao, S. Chen, G. Xie, G. Zhang, C. Zhou and S. Gao, CrystEngComm, 2013, 15, 86; (b) J.-Y. Wua, C.-W. Yang, H.-F. Chen, Y.-C. Jao, S.-M. Huang, C. Tsai, T.-W. Tseng, G.-H. Lee, S.-M. Peng and K.-L. Lu, J. Solid State Chem., 2011, 184, 1740; (c) Y. G. Sun, X. Song, L. Wang, W. Yu, Y. Q. Wang, G. Xiong, M. Y. Guo and E. J. Gao, Russ. J. Coord. Chem., 2011, 37, 316; (d) Y.-Q. Sun, J. Zhang and G.-Y. Yang, Chem. Commun., 2006, 1947.

7 (a) M. H. Alkordi, J. A. Brant, L. Wojtas, V. Ch. Kravtsov, A. J. Cairns and M. Eddaoudi, J. Am. Chem. Soc., 2009, 131, 17753; (b) X.-F. Lin, Acta Crystallogr., Sect. E: Struct. Rep. Online, 2006, 62, m2039; (c) S. Gao, C.-S. Gu, J. Y. Lu and Z. Ge, Inorg. Chim. Acta, 2005, 358, 828; (d) L.-H. Huo, H. Zhao and J.-G. Zhao, Acta Crystallogr., Sect. E: Struct. Rep. Online, 2004, 60, m1672.

8 (a) Z.-G. Gu, H.-C. Fang, P.-Y. Yin, L. Tong, Y. Ying, S.-J. Hu, W.-S. Li and Y.-P. Cai, Cryst. Growth Des., 2011, 11, 2220; (b) S.-Q. Zhang, F.-L. Jiang, M.-Y. Wu, R. Feng, J. Ma, W.-T. Xu and M.-C. Hong, Inorg. Chem. Commun., 2011, 14, 1400; (c)
W. Wang, X. Niu, Y. Gao, Y. Zhu, G. Li, H. Lu and M. Tang, Cryst. Growth Des., 2010, 10, 4050; (d) W.-G. Lu, L. Jiang and T.-B. Lu, Cryst. Growth Des., 2010, 10, 4310; (e) X. Jing, H. Meng, G. Li, Y. Yu, Q. Huo, M. Eddaoudi and Y. Liu, Cryst. Growth Des., 2010, 10, 3489.

9 (a) X. Li, B.-L. Wu, C.-Y. Niu, Y.-Y. Niu and H.-Y. Zhang, Cryst. Growth Des., 2009, 9, 3423; (b) W.-G. Lu, L. Jiang, X.-L. Feng and T.-B. Lu, Cryst. Growth Des., 2008, 8, 986; (c) J.-D. Lin, J.-W. Cheng and S.-W. Du, Cryst. Growth Des., 2008, 8, 3345; (d) W. Liu, L. Ye, X. Liu, L. Yuan, X. Lu and J. Jiang, Inorg. Chem. Commun., 2008, 11, 1250; (e) R.-Q. Zhong, R.-Q. Zou and Q. Xu, Microporous Mesoporous Mater., 2007, 102, 122; $(f)$ R.-Q. Fang and X.-M. Zhang, Inorg. Chem., 2006, 45, 4801; (g) Y.-Q. Sun, J. Zhang and G.-Y. Yang, Chem. Commun., 2006, 4700; (h) W.-G. Lu, L. Jiang, X.-L. Feng and T.-B. Lu, Cryst. Growth Des., 2006, 6, 564; (i) P. Mahata and S. Natarajan, Eur. J. Inorg. Chem., 2005, 2156; ( $j$ ) Y.-Q. Sun, J. Zhang, Y.-M. Chen and G.-Y. Yang, Angew. Chem., Int. Ed., 2005, 44, 5814.

10 (a) S. Wang, T. Zhao, G. Li, L. Wojtas, Q. Huo, M. Eddaoudi and Y. Liu, J. Am. Chem. Soc., 2010, 132, 18038; (b) Y. Liu, V. C. Kravtsov and M. Eddaoudi, Angew. Chem., Int. Ed., 2008, 47, 8446; (c) J.-Z. Gu, W.-G. Lu, L. Jiang, H.-C. Zhou and T.-B. Lu, Inorg. Chem., 2007, 46, 5835; (d) T. K. Maji, G. Mostafa, H.-C. Changa and S. Kitagawa, Chem. Commun., 2005, 2436; (e) F. Zhang, Z. Li, T. Ge, H. Yao, G. Li, H. Lu and Y. Zhu, Inorg. Chem., 2010, 49, 3776; $(f)$ X. Li, B. Wu, R. Wang, H. Zhang, C. Niu, Y. Niu and H. Hou, Inorg. Chem., 2010, 49, 2600; (g) Q. Xu, R.-Q. Zou, R.-Q. Zhong, C. KachiTerajima and S. Takamizawa, Cryst. Growth Des., 2008, 8, 2458; (h) M.-B. Zhang, Y.-M. Chen, S.-T. Zheng and G.-Y. Yang, Eur. J. Inorg. Chem., 2006, 1423; (i) C.-J. Li, S. Hu, W. Li, C.-K. Lam, Y.-Z. Zheng and M.-L. Tong, Eur. J. Inorg. Chem., 2006, 1931; (j) Y.-L. Wang, D.-Q. Yuan, W.-H. Bi, X. Li, X.-J. Li, F. Li and R. Cao, Cryst. Growth Des., 2005, 5, 1849; (k) W.-G. Lu, J.-Z. Gu, L. Jiang, M.-Y. Tan and T.-B. Lu, Cryst. Growth Des., 2005, 8, 192; (l) X. Zhang, D. Huang, F. Chen, C. Chen and Q. Liu, Inorg. Chem. Commun., 2004, 7, 662; (m) M. H. Alkordi, Y. Liu, R. W. Larsen, J. F. Eubank and M. Eddaoudi, J. Am. Chem. Soc., 2008, 130, 12639; (n) R.-Q. Zou, H. Sakurai and Q. Xu, Angew. Chem., Int. Ed., 2006, 45, 2542; (o) W.-G. Lu, L. Jiang, X.-L. Feng and T.-B. Lu, Inorg. Chem., 2009, 48, 6997; (p) Y. Liu, V. C. Kravtsov, R. Larsen and M. Eddaoudi, Chem. Commun., 2006, 1488; (q) W.-G. Lu, C.-Y. Su, T.-B. Lu, L. Jiang and J.-M. Chen, J. Am. Chem. Soc., 2006, 128, 34.

11 (a) C.-D. Wu, A. Hu, L. Zhang and W. Lin, J. Am. Chem. Soc., 2005, 127, 8940; (b) R. Kitaura, G. Onoyama, H. Sakamoto, R. Matsuda, S. Noro and S. Kitagawa, Angew. Chem., Int. Ed., 2004, 43, 2684; (c) Q.-H. Fan, Y.-M. Li and A. S. C. Chan, Chem. Rev., 2002, 102, 3385.

12 (a) D. Bourissou, O. Guerret, F. P. Gabbaï and G. Bertrand, Chem. Rev., 2000, 100, 39; (b) W. A. Hermann, Angew. Chem., Int. Ed., 2002, 41, 1290; (c) ed. F. Glorious, N-Heterocyclic carbenes in transition metal catalysis, Topics in Organometallic Chemistry, Springer-Verlag, Berlin/Heidelberg, 2007, vol. 21. 
13 J. Yoon, S. K. Kim, N. J. Singh and K. S. Kim, Chem. Soc. Rev., 2006, 35, 355.

14 (a) J. M. Roberts, O. K. Farha, A. A. Sarjeant, J. T. Hupp and K. A. Scheidt, Cryst. Growth Des., 2011, 11, 4747; (b) K. Oisaki, Q. Li, H. Furukawa, A. U. Czaja and O. M. Yaghi, J. Am. Chem. Soc., 2010, 132, 9262; (c) R. S. Crees, M. L. Cole, L. R. Hanton and C. J. Sumby, Inorg. Chem., 2010, 49, 1712; (d) X.-C. Chai, Y.-Q. Sun, R. Lei, Y.-P. Chen, S. Zhang, Y.-N. Cao and H.-H. Zhang, Cryst. Growth Des., 2010, 10, 658; (e) J. Chun, I. G. Jung, H. J. Kim, M. Park, M. S. Lah and S. U. Son, Inorg. Chem., 2009, 48, 6353; $(f)$ L. Liu, Z. Li, B. Wang, G. Li, L. Wang, X. Meng and Z. He, Cryst. Growth Des., 2009, 9, 5244; (g) L. Han, S. Zhang, Y. Wang, X. Yan and X. Lu, Inorg. Chem., 2009, 48, 786; $(h)$ Z. Fei, T. J. Geldbach, R. Scopelliti and P. J. Dyson, Inorg. Chem., 2006, 45, 6331; $(j)$ Z. Fei, T. J. Geldbach, D. Zhao, R. Scopelliti and P. J. Dyson, Inorg. Chem., 2005, 44, 5200.

15 V. Karthik, I. A. Bhat and G. Anantharaman, Organometallics, 2013, 32, 7006.

16 C. Mohapatra, S. Tripathi, G. Anantharaman and V. Chandrasekhar, Cryst. Growth Des., 2014, 14, 3182.

17 (a) M. P. Hay, W. R. Wilson and W. A. Denny, Tetrahedron, 2000, 56, 645; (b) K. Hara, Y. Kanamori and M. Sawamura, Bull. Chem. Soc. Jpn., 2006, 79, 1781.

18 G. M. Sheldrick, SHELXL-97, Program for Crystal Structure Solution and Refinement; University of Göttingen, Göttingen, Germany, 1997.
19 V. A. Blatov, Multipurpose crystallochemical analysis with the program package TOPOS, IUCr CompComm Newsletter, 2006, vol. 7, p. 4, http://www.topos.ssu.samara.ru.

20 G. B. Deacon and R. J. Phillips, Coord. Chem. Rev., 1980, 33, 22.

21 R. Koner and I. Goldberg, Acta Crystallogr., Sect. C: Cryst. Struct. Commun., 2009, 65, m37.

22 (a) G. R. Desiraju, Acc. Chem. Res., 2002, 35, 565; (b) D. Braga, F. Grepioni and G. R. Desiraju, J. Organomet. Chem., 1997, 548, 33; (c) G. R. Desiraju, Acc. Chem. Res., 1996, 29, 441; (d) G. R. Desiraju, Acc. Chem. Res., 1991, 24, 290.

23 (a) S. P. Thomas, M. S. Pavan and T. N. G. Row, Chem. Commun., 2014, 50, 49; (b) G. Bhattacharjya, G. Savithaa and G. Ramanathan, CrystEngComm, 2004, 6, 233.

24 R. Alizadeh, K. Kalateh, Z. Khoshtarkib, R. Ahmadi and V. Amani, Acta Crystallogr., Sect. E: Struct. Rep. Online, 2009, 65, m1439.

25 (a) J. Heine and K. Müller-Buschbaum, Chem. Soc. Rev., 2013, 42, 9232; (b) Y. Cui, Y. Yue, G. Qian and B. Chen, Chem. Rev., 2012, 112, 1126; (c) M. D. Allendorf, C. A. Bauer, R. K. Bhakta and R. J. T. Houk, Chem. Soc. Rev., 2009, 38, 1330.

26 C. Banglin, W. Liangbo, Z. Fatima, Q. Guodong and E. B. Lobkovsky, J. Am. Chem. Soc., 2008, 130, 6718.

27 P. Chakraborty, S. Mondal, S. Das, A. D. Jana and D. Das, Polyhedron, 2014, 70, 11. 